\title{
Everyman's Guide to Bacterial Insertion Sequences
} PATRICIA SIGUIER, ${ }^{1}$ EDITH GOURBEYRE, ${ }^{1}$ ALESSANDRO VARANI, $^{2}$
BAO TON-HOANG, ${ }^{1}$ and MICK CHANDLER ${ }^{1}$

\author{
${ }^{1}$ Laboratoire de Microbiologie et Génétique Moléculaires, CNRS, Toulouse, France; \\ ${ }^{2}$ Departamento de Tecnologia, Faculdade de Ciências Agrárias e Veterinárias de Jaboticabal, \\ UNESP - Univ. Estadual Paulista, Jaboticabal, SP, Brazil
}

\begin{abstract}
The number and diversity of known prokaryotic insertion sequences (IS) have increased enormously since their discovery in the late 1960s. At present the sequences of more than 4000 different IS have been deposited in the specialized ISfinder database. Over time it has become increasingly apparent that they are important actors in the evolution of their host genomes and are involved in sequestering, transmitting, mutating and activating genes, and in the rearrangement of both plasmids and chromosomes. This review presents an overview of our current understanding of these transposable elements (TE), their organization and their transposition mechanism as well as their distribution and genomic impact. In spite of their diversity, they share only a very limited number of transposition mechanisms which we outline here. Prokaryotic IS are but one example of a variety of diverse TE which are being revealed due to the advent of extensive genome sequencing projects. A major conclusion from sequence comparisons of various TE is that frontiers between the different types are becoming less clear. We detail these receding frontiers between different IS-related TE. Several, more specialized chapters in this volume include additional detailed information concerning a number of these.

In a second section of the review, we provide a detailed description of the expanding variety of IS, which we have divided into families for convenience. Our perception of these families continues to evolve and families emerge regularly as more IS are identified. This section is designed as an aid and a source of information for consultation by interested specialist readers.
\end{abstract}

\section{INTRODUCTION}

We have divided this review into two major sections. In one, we have attempted to present an overview of our current understanding of prokaryotic insertion sequences (IS), their diversity in sequence, in organization and in mechanism, their distribution and impact on their host genome, and their relation to their eukaryotic cousins. We discuss several IS-related transposable elements (TE) which have been identified since the previous edition of Mobile DNA. These include IS that use single-strand DNA intermediates and their related "domesticated" relations, insertion sequences with a common region (ISCR), and integrative conjugative elements (ICE), which use IS-related transposases (Tpases) for excision and integration. Several more specialized chapters in this volume include additional detailed information concerning a number of these topics. One of the major conclusions from this section is that the frontiers between the different types of TE are becoming less clear as more are identified. In the second part, we have provided a detailed description of the expanding variety of IS, which we have divided into families for convenience. We emphasize that there is no "quantitative" measure of the weight of each of the criteria we use to define a family. Our perception of these families continues to evolve and families emerge regularly as more IS are added. This section is designed as an aid and a source of information for consultation by interested specialist readers.

Received: 6 June 2014, Accepted: 29 January 2015, Published: 2 April 2015

Editors: Mick Chandler, Université Paul Sabatier, Toulouse, France, and Nancy Craig, Johns Hopkins University, Baltimore, MD

Citation: Siguier P, Gourbeyre E, Varani A, Ton-Hoang B, Chandler M. 2015. Everyman's guide to bacterial insertion sequences. Microbiol Spectrum 3(2):MDNA3-0030-2014. doi:10.1128 Imicrobiolspec.MDNA3-0030-2014.

Correspondence: Mick Chandler, mike.chandler@ibcg.biotoul.fr (c) 2015 American Society for Microbiology. All rights reserved. 


\section{HISTORY}

It is now over 40 years since the first IS were described. They were identified as short DNA segments found repeatedly associated with mutations in the gal operon and bacteriophage $\lambda(\underline{1}-\underline{3})$. Shortly after, it was established that IS were normal residents of the Escherichia coli chromosome (4) sometimes present in multiple copies. They were shown to be involved in generating deletions $(\underline{5})$ and in activating gene expression (6). They were also identified as constituents of bacterial plasmids (7). At about the same time, it was observed that antibiotic resistance genes could also be transferred or "transposed" from one plasmid to another $(\underline{8}-10)$ and it was recognized that IS and "transposons" were both members of a group of genetic entities: transposable or mobile genetic elements (TE or MGE). This relationship between IS and transposons was reinforced by the observation that different DNA segments carrying different genes could be translocated by two flanking IS $(11,12)$. It was also realized (13) that they might be related to the controlling elements discovered by genetic analysis of maize several decades previously (14).

However, in spite of the observation that IS can be present in some bacterial species in extremely high copy numbers $(15,16)$, little at the time prepared us for the subsequent recognition of the preponderant role they play in shaping genomes, of their extreme diversity and their widespread distribution (see reference 17).

\section{WHAT IS AN IS?}

The original definition of an IS was: a short, generally phenotypically cryptic, DNA segment encoding only the enzymes necessary for its transposition and capable of repeated insertion into many different sites within a genome using mechanisms independent of large regions of DNA homology between the IS and target $(18,19)$. Classical IS are between 0.7 and $2.5 \mathrm{~kb}$ in length, genetically compact with one or two open reading frames (orfs) which occupy the entire length of the IS and terminate in flanking imperfect terminal repeat sequences (IR). The orfs include the Tpase that catalyzes the DNA cleavages and strand transfers leading to IS movement and, in some cases, regulatory proteins. Their highly compact nature is illustrated by the fact that some IS have developed "recoding" strategies such as Programmed Ribosomal Frameshifting (involving ribosome slippage) and Programmed Transcriptional Realignment (involving RNA polymerase slippage) (Chandler et al., this volume; $(20,21))$. These permit assembly of different functional protein domains effectively encoding two proteins of different function in one DNA segment. IS also often generate a short flanking directly repeated duplication (DR) of the target on insertion. These characteristics are not limited to prokaryotic IS but are also shared with most eukaryotic DNA transposons. However, for prokaryotic IS, this strict definition has been broadened over the years with the discovery of an increasing number of noncanonical derivatives and variants, some of which are described below. Moreover, as we learn more about diversity from sequenced genomes, classification is becoming more problematic because the large degree of MGE diversity is obscuring the borders between certain types of TE (see Fuzzy Borders section) (20).

Despite their abundance and diversity, the number of different chemical mechanisms used in TE movement is surprisingly limited and many quite divergent TE share a similar mechanism.

\section{ISFINDER AND THE GROWING NUMBERS OF IS}

Since 1998, IS have been centralized in the ISfinder database (www-is.biotoul.fr). This provides a basic framework for nomenclature and IS classification into related groups or families (22). Initially IS were each assigned a simple number (23). However, to provide information about their provenance, IS nomenclature rules were changed and now resemble those used for restriction enzymes: with the first letter of the genus followed by the first two letters of the species and a number (24) (e.g., ISBce1 for Bacillus cereus).

In 1977 only five IS (IS1, IS2, IS3, IS4, and IS5) had been identified (13). At the time of publication of the first edition of Mobile DNA this had risen to 50 (25); at the time of the second edition, there were more than 700 (26). Currently, ISfinder includes more than 4,000 different IS. This represents only a fraction of IS present in the public databases. Not only has the number of IS identified increased dramatically with the advent of high-throughput genome sequencing but examination of the public databases has shown that genes annotated as Tpases, the enzymes that catalyze TE movement (or proteins with related functions), are by far the most abundant functional class (17).

\section{MAJOR IS GROUPS ARE DEFINED BY THE TYPE OF TRANSPOSASE THEY USE}

Insertion sequences can be grouped into families but, in the first instance, the principal division in IS classifica- 
tion is based on the nature of their Tpases (Table 1). These can be divided into two major types based on the chemistry used in breaking and re-joining DNA during TE displacement: the DDE (and DEDD) and $\mathrm{HUH}$ enzymes.

\section{DDE transposases}

DDE enzymes, so-called because of a conserved Asp, Asp, Glu triad of amino acids that coordinate essential metal ions, use $\mathrm{OH}$ (e.g., $\mathrm{H}_{2} \mathrm{O}$ ) as a nucleophile in a transesterification reaction (27) (Hickman and Dyda, this volume). They do not form covalent Tpase-DNA intermediates during the transposition process.

Insertion sequences with DDE enzymes are the most abundant type in the public databases. This is partly because the definition of an IS became implicitly coupled to the presence of a DDE Tpase, an idea probably reinforced by the similarity between Tpases of IS (and other prokaryotic and eukaryotic TE) and the retroviral integrases $(\underline{28}-\underline{30})$ particularly in the region including the catalytic site. More precisely, for these TE, the triad is $\mathrm{DD}(35) \mathrm{E}$ in which the second $\mathrm{D}$ and $\mathrm{E}$ are separated by 35 residues. As more DDE Tpases were identified, the distance separating the $\mathrm{D}$ and $\mathrm{E}$ residues was found to vary slightly. However, for certain IS, this distance was significantly larger. In these cases, the Tpases include an "insertion domain" between the second $\mathrm{D}$ and $\mathrm{E}$ residues (31) with either $\alpha$-helical or $\beta$-strand configurations. Although in most cases this is a prediction, it has been confirmed by crystallographic studies for the IS50 ( $\beta$-strand) (32) and Hermes ( $\alpha$-helical) (33) Tpases. The function of these "insertion domains" is not entirely clear.

Although DDE-type transposons share basic transposition chemistry, different TE vary in the steps leading to formation of an insertion intermediate that has shed flanking donor DNA (Figure 1) (Hickman and Dyda, this volume). They catalyze cleavage of a single DNA strand to generate a $3^{\prime} \mathrm{OH}$ at the TE ends, which is subsequently used as a nucleophile to attack the DNA target phosphate backbone. This is known as the transferred strand. The variations are a result of the way in which the second (nontransferred) strand is processed $(34,35)$. There are several ways in which second-strand processing can occur (Figure 1).

For certain IS, the second strand is not cleaved but replication following transfer of the first strand fuses donor and target molecules to generate cointegrates with a directly repeated copy at each donor/target junction. This is known as replicative transposition (e.g., IS6, Tn3) or more precisely, target primed replicative transposition (Figure 1, first column).
In the other pathways, the flanking donor DNA can be shed in several different ways.

The nontransferred strand may be cleaved initially several bases within the IS before cleavage of the transferred strand (e.g., IS630 and Tc1) $(\underline{36}, 37)$ (Figure 1, second column).

The 3' $\mathrm{OH}$ generated by first-strand cleavage may be used to attack the second strand to form a hairpin structure at the IS ends liberating the IS from flanking DNA and subsequently hydrolyzed to regenerate the 3' $\mathrm{OH}$ (conservative or cut-and-paste transposition; e.g., IS4; Haniford and Ellis, this volume) (Figure 1, third column).

The 3' $\mathrm{OH}$ of the transferred strand from one IS end may attack the other to generate a donor molecule with a single-strand bridge that is then replicated to produce a double-strand transposon circle intermediate and regenerating the original donor molecule (Copy out-Paste in or more precisely donor primed transposon replication, e.g., IS3; Chandler et al, this volume) (Figure 1, fourth column).

Or finally, the $3^{\prime} \mathrm{OH}$ at the flank of the nontransferred strand may attack the second strand to form a hairpin on the flanking DNA and a $3^{\prime} \mathrm{OH}$ on the transferred strand (at present this has only been demonstrated for eukaryotic TE of the hAT family and in V (D)J recombination (38).

Clearly, many families produce double-strand circular intermediates but this does not necessarily mean that they all use the Copy out-Paste in donor primed transposon replication mechanism because a circle could be generated by excision involving recombination of both strands (see Hickman and Dyda, this volume). These differences are reflected in the different IS families.

\section{DEDD transposases}

A similar type of Tpase, known as a DEDD Tpase, is related to the Holliday junction resolvase, RuvC $(39,40)$. These possess a similar predicted structural topology in their catalytic site and presumably have similar chemistry to the DDE enzymes. They are at present limited to a single IS family (IS110). They also exhibit a different order in their functional domains compared with most DDE Tpases: with the catalytic domain N-terminal to the DNA-binding domain. In addition, the associated IS do not have significant terminal IR and insertion does not necessarily generate direct target repeats. Hence, while the transposition chemistry may be similar to that of the DDE Tpases, the overall transposition mechanism is probably different. 
TABLE 1 Characteristics of insertion sequence families

\begin{tabular}{|c|c|c|c|c|c|c|c|c|c|c|}
\hline Families & Sub-groups & $\begin{array}{l}\text { Typical } \\
\text { size-range }\end{array}$ & DR (bp) & Ends & IRs & $\begin{array}{l}\text { No. of } \\
\text { ORF }\end{array}$ & Frameshift & $\begin{array}{l}\text { Catalytic } \\
\text { residues }\end{array}$ & Comments & Mechanism \\
\hline IS1 & $\begin{array}{l}- \\
\text { single ORF } \\
\text { ISMhu11 }\end{array}$ & $\begin{array}{l}740-1,180 \\
800-1,200 \\
900-4,600\end{array}$ & $\begin{array}{l}8-9 \\
0-9 \\
0-10\end{array}$ & GGnnnTG & $\begin{array}{l}Y \\
Y\end{array}$ & $\begin{array}{l}2 \\
1 \\
2\end{array}$ & $\begin{array}{l}\text { ORFAB } \\
\text { ORFAB }\end{array}$ & DDE & & $\begin{array}{l}\text { copy-and-paste } \\
\text { and cointegrate }\end{array}$ \\
\hline IS1595 & $\begin{array}{l}\text { ISPna2 } \\
\text { ISPna2+pass } \\
\text { ISH4 } \\
\text { IS1016 } \\
\text { IS1595 } \\
\text { ISSOd11 } \\
\text { ISNwi1 } \\
\text { ISNwi1+pass } \\
\text { ISNha5 }\end{array}$ & $\begin{array}{l}1,000-1,150 \\
1,500-2,600 \\
1,000 \\
700-745 \\
900-1,100 \\
1,000-1,100 \\
1,080-1,200 \\
1,750-4,750 \\
3,450-7,900\end{array}$ & $\begin{array}{l}8 \\
8 \\
8 \\
7-9 \\
8 \\
8 \\
8 \\
8 \\
8\end{array}$ & $\begin{array}{l}\text { GGCnnTG } \\
\text { CGCTCTT } \\
\text { GGGgctg } \\
\text { CcTGATT } \\
\text { nnnGCnTATC } \\
\text { ggnnatTAT } \\
\text { CGGnnTT }\end{array}$ & Y & $\begin{array}{l}1 \\
1 \\
1 \\
1 \\
1 \\
1 \\
1 \\
1\end{array}$ & & $\begin{array}{l}\text { DDNK } \\
\text { DDNK } \\
\text { DDEK } \\
\text { DDNK + ER4R7 } \\
\text { DDHK + ER4R7 } \\
\text { DDEK + ER4 } \\
\text { DDER/K }\end{array}$ & & copy-and-paste? \\
\hline IS3 & $\begin{array}{l}\text { IS150 } \\
\text { IS407 } \\
\text { IS51 } \\
\text { IS3 } \\
\text { IS2 }\end{array}$ & $\begin{array}{l}1,200-1,600 \\
1,100-1,400 \\
1,000-1,400 \\
1,150-1,750 \\
1,300-1,400\end{array}$ & $\begin{array}{l}3-4 \\
4 \\
3-4 \\
3-4 \\
5\end{array}$ & $\begin{array}{l}\text { TG } \\
\text { TG } \\
\text { TG } \\
\text { TGa/g } \\
\text { TG }\end{array}$ & Y & 2 & ORFAB & DDE & & copy-paste \\
\hline IS481 & - & $950-1,300$ & $4-15$ & TGT & Y & 1 & & DDE & & copy-paste? \\
\hline ISNCY & IS1202 & $1,400-1,700$ & 5 & TGT & Y & 1 & & DDEQ & & \\
\hline IS4 & $\begin{array}{l}\text { IS10 } \\
\text { IS50 } \\
\text { ISPepr1 } \\
\text { IS4 } \\
\text { IS4Sa } \\
\text { ISH8 } \\
\text { IS } 231\end{array}$ & $\begin{array}{l}1,200-1,350 \\
1,350-1,550 \\
1,500-1,600 \\
1,400-1,600 \\
1,150-1,750 \\
1,400-1,800 \\
1,450-5,400\end{array}$ & $\begin{array}{l}9 \\
8-9 \\
7-8 \\
10-13 \\
8-10 \\
10 \\
10-12\end{array}$ & $\begin{array}{l}\text { CT } \\
\text { C } \\
\text {-T-AA } \\
\text {-AAT } \\
\text { CA } \\
\text { CAT } \\
\text { CAT }\end{array}$ & Y & 1 or + * & & DDE & $\begin{array}{l}\text { Hairpin } \\
\text { intermediate } \\
\text { Hairpin } \\
\text { intermediate } \\
? \\
? \\
? \\
? \\
\text { * Passenger genes }\end{array}$ & cut-and-paste \\
\hline IS701 & ISAba11 & $1,400-1,550$ & 4 & & $\begin{array}{l}Y \\
Y\end{array}$ & $\begin{array}{l}1 \\
1\end{array}$ & & $\begin{array}{l}\text { DDE } \\
\text { DDE }\end{array}$ & & \\
\hline $\mathrm{ISH} 3$ & - & $1,225-1,500$ & $4-5$ & C-GT & Y & 1 & & DDE & & \\
\hline IS1634 & - & $1,500-2,000$ & $5-6$ & C & Y & 1 & & DDE & & \\
\hline
\end{tabular}




\begin{tabular}{|c|c|c|c|c|c|c|c|c|c|c|}
\hline IS5 & $\begin{array}{l}\text { IS903 } \\
\text { ISL2 } \\
\text { ISH1 } \\
\text { IS5 } \\
\text { IS1031 } \\
\text { IS427 }\end{array}$ & $\begin{array}{l}950-1,150 \\
850-1,200 \\
900-1,150 \\
1,000-1,500 \\
850-1,050 \\
800-1,000\end{array}$ & $\begin{array}{l}9 \\
2-3 \\
8 \\
4 \\
3 \\
2-4\end{array}$ & $\begin{array}{l}G G \\
-G C \\
G a / g \\
G A a / g \\
G a / g\end{array}$ & Y & $\begin{array}{l}1 \\
1 \\
1 \\
1 \\
1 \\
2\end{array}$ & ORFAB & DDE & & \\
\hline IS1182 & - & $1,330-1,950$ & $0-60$ & & Y & 1 & & DDE & & \\
\hline ISNCY & ISDol1 & $1,600-1,900$ & $6-7$ & & Y & 1 & & DDE & & \\
\hline IS6 & - & $700-900$ & 8 & $G G$ & Y & 1 & & DDE & & co-integrate \\
\hline IS21 & - & $1,750-2,600$ & $4-8$ & TG & Y & 2 * & & DDE & $\begin{array}{l}\text { * istB: transposition } \\
\text { helper }\end{array}$ & \\
\hline IS30 & - & $1,000-1,700$ & $2-3$ & & Y & 1 & & DDE & & copy-and-paste \\
\hline IS66 & $\begin{array}{l}- \\
\text { ISBst12 }\end{array}$ & $\begin{array}{l}2,000-3,000 \\
1,350-1,900\end{array}$ & $\begin{array}{l}8-9 \\
8-9\end{array}$ & $\begin{array}{l}\text { GTAA } \\
\text { GTAA }\end{array}$ & $\begin{array}{l}Y \\
Y\end{array}$ & $\begin{array}{l}3 * \\
1\end{array}$ & & $\begin{array}{l}\mathrm{DDE} \text { * } \\
\mathrm{DDE}\end{array}$ & $\begin{array}{l}\text { * TnpC has the } \\
\text { DDE domain }\end{array}$ & \\
\hline IS256 & $\begin{array}{l}- \\
\text { IS1249 } \\
\text { ISC1250 }\end{array}$ & $\begin{array}{l}1,200-1,500 \\
1,300 \\
1,250\end{array}$ & $\begin{array}{l}8-9 \\
0-10 \\
0-9\end{array}$ & $\begin{array}{l}\mathrm{Ga} / \mathrm{g} \\
\mathrm{GG} \\
\mathrm{GG}\end{array}$ & $\begin{array}{l}Y \\
Y \\
Y\end{array}$ & $\begin{array}{l}1 \\
1 \\
1\end{array}$ & & $\begin{array}{l}\text { DDE } \\
\text { DDE } \\
\text { DDE }\end{array}$ & & copy-paste \\
\hline ISH6 & - & 1,450 & 8 & GGT & Y & 1 & & DDE & & \\
\hline ISLre2 & - & $1,500-2,000$ & 9 & & Y & 1 & & DDE & & \\
\hline ISKra4 & $\begin{array}{l}\text { ISAzba1 } \\
\text { ISMich2 } \\
\text { ISKra4 }\end{array}$ & $\begin{array}{l}1,400-2,900 \\
1,250-1,400 \\
1,400-3,700\end{array}$ & $\begin{array}{l}0 \\
8 \\
9\end{array}$ & $\begin{array}{l}\text { GGG } \\
\text { GGG }\end{array}$ & $\begin{array}{l}Y \\
Y \\
Y\end{array}$ & $\begin{array}{l}1 \text { or }+* \\
1 \text { or } 2 \\
1 \text { or }+^{*}\end{array}$ & ORFAB & $\begin{array}{l}\text { DDE } \\
\text { DDE } \\
\text { DDE }\end{array}$ & $\begin{array}{l}\text { * Passenger genes } \\
\text { * Passenger genes }\end{array}$ & \\
\hline IS630 & - & $1,000-1,400$ & 2 * & & Y & 1 or 2 & ORFAB & DDE & $\begin{array}{l}\text { * Target site: } \\
\text { often NTAN with } \\
\text { duplication of the TA }\end{array}$ & cut-and-paste \\
\hline IS982 & - & 1,000 & $3-9$ & $A C$ & Y & 1 & & DDE & & \\
\hline IS1380 & - & $1,550-2,000$ & $4-5$ & $\mathrm{CC}$ & Y & 1 & & DDE & & \\
\hline ISAs1 & - & $1,200-1,500$ & $8-10$ & CAGGG & Y & 1 & & & & \\
\hline ISL3 & - & $1,300-2,300$ & 8 & GG & Y & 1 & & & & \\
\hline Tn3 & - & $>3,000$ & 0 & GGGG & Y & $>1$ & & DDE & & co-integrate \\
\hline
\end{tabular}

(continued) 


\begin{tabular}{|c|c|c|c|c|c|c|c|c|c|c|}
\hline Families & Sub-groups & $\begin{array}{l}\text { Typical } \\
\text { size-range }\end{array}$ & DR (bp) & Ends & IRs & $\begin{array}{l}\text { No. of } \\
\text { ORF }\end{array}$ & Frameshift & $\begin{array}{l}\text { Catalytic } \\
\text { residues }\end{array}$ & Comments & Mechanism \\
\hline ISAzo13 & - & $1,250-2,200$ & $0-4$ & $\mathrm{Ga} / \mathrm{g}$ & $Y$ & 1 & & & & \\
\hline IS110 & IS1111 & $1,200-1,550$ & 0 & & $\begin{array}{l}N \\
Y *\end{array}$ & 1 & & DEDD & $\begin{array}{l}\text { * IRs not at the } \\
\text { termini of the IS }\end{array}$ & \\
\hline IS91 & - & $1,500-2,000$ & 0 & & $N$ & 1 & & $\mathrm{HUH} / \mathrm{Y} 2$ & $\begin{array}{l}\text { Target site GAAC ( ) } \\
\text { CAAG }\end{array}$ & rolling circle \\
\hline IS200/IS605 & $\begin{array}{l}\text { IS200 } \\
\text { IS605 } \\
\text { IS1341 }\end{array}$ & $\begin{array}{l}600-750 \\
1,300-2,000 \\
1,200-1,500\end{array}$ & 0 & & $\mathrm{~N}$ & $\begin{array}{l}1 \text { * } \\
2 \text { * } \\
1 \text { * }\end{array}$ & & 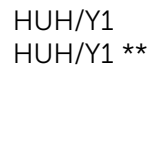 & $\begin{array}{l}\text { * TnpA } \\
\text { * TnpA + TnpB } \\
\text { ** Y1 on TnpA } \\
\text { * TnpB }\end{array}$ & peel-and-paste \\
\hline IS607 & - & $1,700-2,500$ & 0 & & $\mathrm{~N}$ & 2 * & & Serine ** & $\begin{array}{l}* \operatorname{TnpA}+\operatorname{TnpB} ; * \star \\
\operatorname{TnpA}\end{array}$ & \\
\hline ISNCY & $\begin{array}{l}\text { IS892 } \\
\text { ISLbi1 } \\
\text { ISMae2 } \\
\text { ISPlu15 } \\
\text { ISA1214 } \\
\text { ISC1217 } \\
\text { ISM1 }\end{array}$ & $\begin{array}{l}1,600 \\
1,400-1,500 \\
1,400-2,400 \\
800-1,000 \\
1,000-1,200 \\
1,200 \\
1,300-1,600\end{array}$ & $\begin{array}{l}0-8 \\
5 \\
9 \\
0 \\
8-12 \\
6-8 \\
8-9\end{array}$ & $\begin{array}{l}\text { CTAG } \\
\text { CAG }\end{array}$ & $\begin{array}{l}Y \\
Y \\
Y \\
N \\
Y \\
Y \\
Y\end{array}$ & $\begin{array}{l}2 \\
1 \\
1 \\
1 \\
2 \\
1 \\
1\end{array}$ & ORFAB & & & \\
\hline
\end{tabular}

Abbreviations: DR, duplication repeat; IS, insertion sequence; ORF, open reading frame. 


\section{HUH transposases}

Named after a conserved pair of His residues separated by a large hydrophobic amino acid (U), the HUH Tpases use tyrosine as a nucleophile and generate a transitory covalent $5^{\prime}$ tyrosine-DNA transposition intermediatefor review see (41) (Hickman and Dyda, this volume; $\mathrm{He}$ et al., this volume).

The TE encoding the second major type of Tpase, called HUH, have been identified more recently. HUH enzymes are widespread single-strand nucleases. They include Rep proteins involved in bacteriophage and plasmid rolling circle replication and relaxases or Mob proteins involved in conjugative plasmid transfer (41). They are limited to two prokaryotic (IS91 and IS200/ IS605; He et al., this volume) and one eukaryotic (helitron; Thomas and Pritham this volume) TE family. As Tpases, they are involved in presumed rolling circle transposition and also in single-strand transposition (see Hickman and Dyda, this volume; He et al., this volume). Their transposition chemistry is radically different to that of DDE group elements. It involves DNA cleavage using a tyrosine residue and transient formation of a $5^{\prime}$ phospho-tyrosine bond between the enzyme and its substrate DNA. In addition, the associated transposons have an entirely different organization and include subterminal secondary structures instead of IR (see IS families section below and He et al., this volume). There are two major HUH Tpase families: Y1 and Y2 enzymes depending on whether there is a single or two catalytic Y residues (41) (Dyda and Hickman, this volume). Although these enzymes use the same Y-mediated cleavage mechanism, IS200/IS605 family Y1 transposases and IS91 transposases appear to carry out the transposition process in quite different ways.

\section{Serine transposases}

A third but minor type of Tpase resembles a site-specific serine recombinase and is at present limited to a single IS family, IS607. These presumably use the catalytic serine to generate a $5^{\prime}$ phospho-serine bond between the enzyme and its substrate DNA in a similar way to serine recombinases such as the $\mathrm{Tn} 3$ resolvase (see chapters by: Stark; Rice; Smith; and Johnson, this volume).

\section{Tyrosine transposases}

Finally, tyrosine site-specific recombinases of the bacteriophage integrase (Int) type are often associated with conjugative transposons (ICE) and are considered to be Tpases. However, at present there are no known IS that use this type of enzyme. These transposases presumably use a catalytic $\mathrm{Y}$ to generate a transitory intermediate with a $3^{\prime}$ phospho-tyrosine bond between the enzyme and its substrate DNA as do the site-specific recombinases (see chapters by Jayaram et al.; van Duyne; Landy; Carraro and Burrus; and Wood and Gardner, this volume) as suggested by early studies with Tn916 (42).

This nomenclature is clearly complex and stems directly from the history of the field. It has often led to confusion in genome annotations in the public databases. The reader is referred to Dyda and Hickman (this volume), He et al., (this volume) and to chapters in the section Conservative Site-Specific Recombination for more detailed descriptions of the overlapping issues of mechanism, function, and structure.

\section{FUZZY BORDERS}

With our increasing knowledge of mobilome diversity (the ensemble of mobile genetic elements including TE, ICE, Genomic Islands [GI], plasmids, phages, and integrons), the distinction between IS and other TE is becoming increasingly unclear. The major feature used to distinguish IS from transposons was that the former (Figure 2A) lack phenotypically detectable passenger genes (genes not involved in the transposition process) whereas the latter include one or more such genes (for antibiotic resistance, virulence and pathogenicity functions or genes permitting the use of unusual compounds). This is no longer the case (Figure 2). Many examples have now been identified in which passenger genes are located within IS or in which TE with typical transposon structures are devoid of transposition proteins.

\section{Transporter IS: IS and relatives with passenger genes}

Over the past few years, a number of TE have been identified that are very closely related to known IS but that carry passenger genes not directly involved in transposition. These are called transporter IS (tIS) (43) (Figure 2C). Passenger genes include transcription regulators (e.g., ISNha5, members of the IS1595 family), methyltransferases (e.g., IS220, IS1380 family), and antibiotic resistance (e.g., ISCgl1, IS481 family) genes. They can include a significant amount of DNA with no clear coding capacity (e.g., ISBse1, ISSpo3, and ISSpo8, IS1595 family) and are longer than typical IS (e.g., ISCausp2, 7,915 bp, IS1595 family). This has presumably delayed their identification. As the second IS end would occur at an unexpectedly distant position, they would resemble partial IS copies lacking a second end. They are never present in high numbers and often only in 


\section{Second Strand Processing of DDE Transposases}

Cointegrate formation

or

Target Primed

Transposon Replication

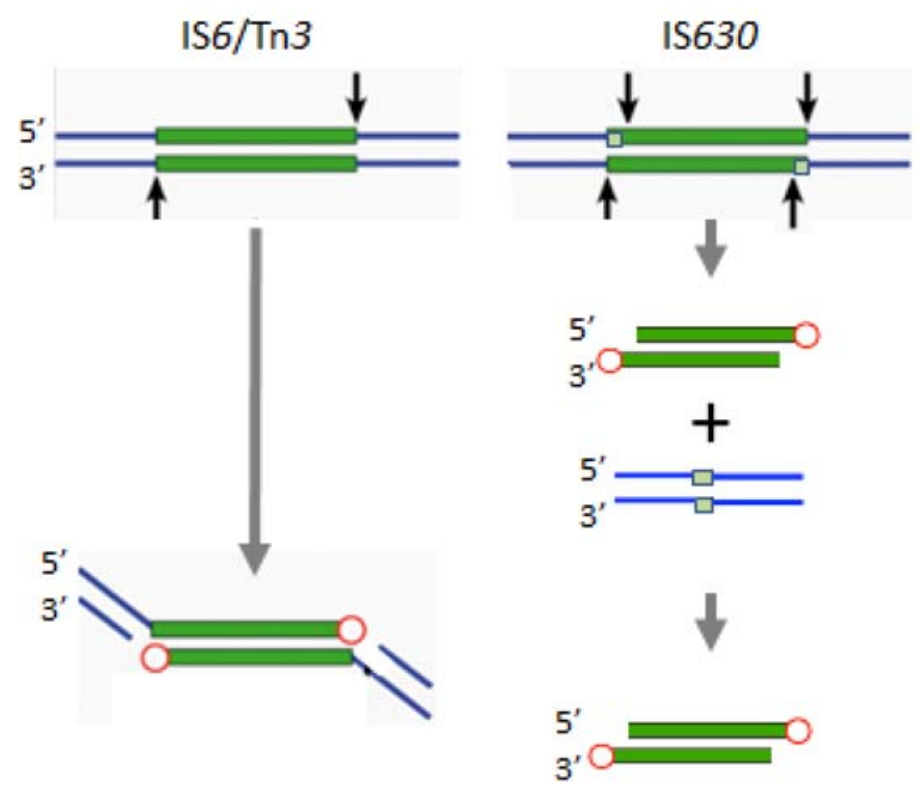

Copy-out-paste-in or

Donor Primed

Transposon Replication

IS3/IS21/IS30/IS256/ISL3
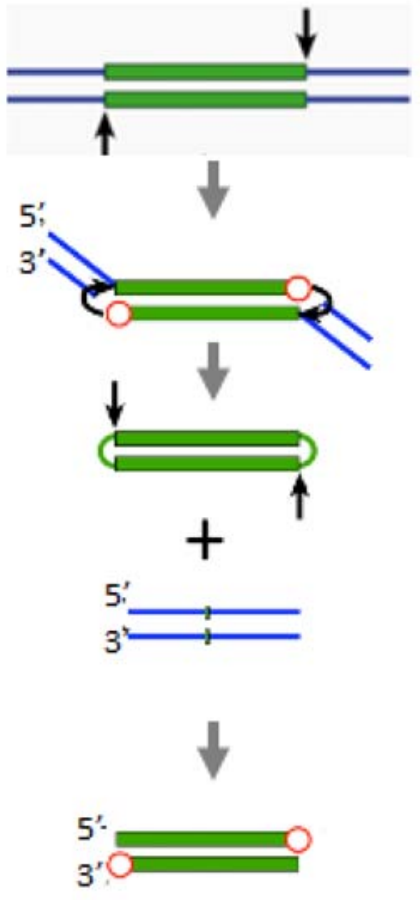

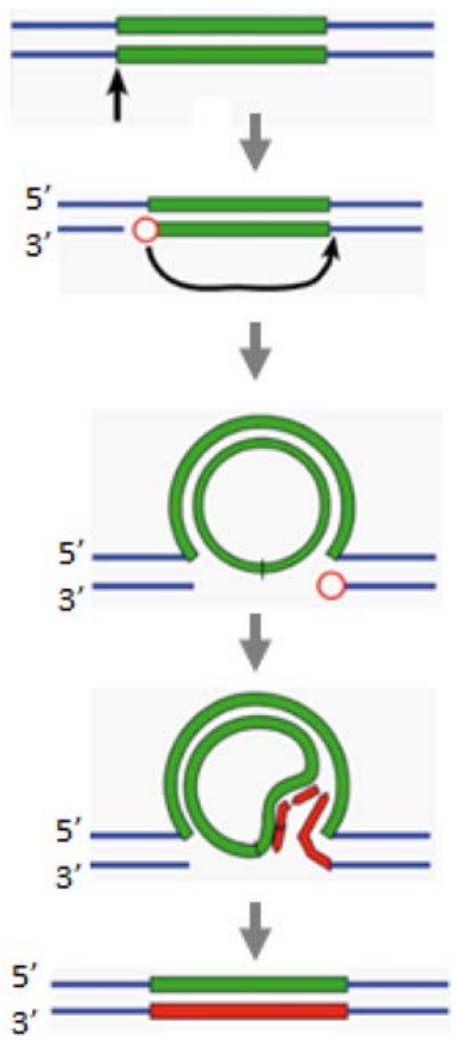

$+$

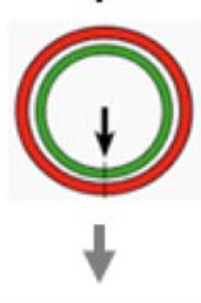

$5^{\prime}$ $3^{\prime} \mathrm{O}=$ 
single copy, suggesting that their transposition activity may be limited.

\section{IS derivatives of Tn3 family transposons}

Another source of ambiguity for classification purposes occurs in the Tn 3 family (Nicolas et al., this volume) (Figure 2B). Tn3 family members are quite variable. They include a number of diverse passenger genes that can represent entire operons, notably mercury resistance, or individual genes involved in antibiotic resistance, breakdown of halogenated aromatics or virulence (44). They often carry integron recombination platforms enabling them to incorporate additional resistance genes by recruiting integron cassettes (45). These are small DNA segments that carry promoterless passenger genes and integrate by site-specific recombination into the integron recombination platform. This platform provides an appropriate resident promoter to govern their expression (see Escudero et al., this volume). Members are characteristic: they have long relatively well-conserved IR and a particularly long Tpase (950 to 1,025 amino acids). They also encode a site-specific recombination ("resolution") system necessary for completion of their transposition (Nicolas et al., this volume). IS1071, composed of Tn3-like IR and Tpase gene but lacking both the site-specific recombination system and passenger genes, was identified many years ago (46). This clearly accords with the definition of an IS. Several other examples have now been identified (e.g., ISVsa19, ISShfr9, ISBusp1).

\section{IS related to ICE}

The ICE, which were initially identified integrate and excise from their host chromosomes using a tyrosinebased enzyme related to phage integrases (47) (Figure 2B) (see chapters by Wood and Gardner and by Carraro and Burrus, this volume). These also carry genes permitting intercellular transfer, although derivatives exist that are not capable of autonomous transfer and are known as IMEs or CIMEs (integrative mobilizable elements; or cismobilizable elements) $(\underline{48}, \underline{49})$. Some, known as GI, also include other types of passenger gene. Depending on the type of passenger genes, GI have been called pathogenicity islands or symbiotic islands.

More recent studies (50-53) have identified ICE with typical DDE Tpases. One group, TnGBS, initially found in Group B Streptococcus, has led to the identification of an entire family of typical insertion sequences, the ISLre2 family (52), whereas another shows a close relationship to IS30 family members (53). The ICE that use typical DDE Tpases also include IR with sequences resembling those of the related IS. Hence it is becoming difficult to draw a distinction between certain GI, ICE and IS.

FIGURE 1 Insertion sequence (IS) families with DDE transposases are distinguished by how the second ("nontransferred") strand is processed. IS are shown in green, flanking DNA in blue. Cleavage is shown as bold vertical arrows. 3' $\mathrm{OH}$ residues are shown as red circles, replicated DNA is indicated in red. The first column shows initial cleavages which generate the $3^{\prime} \mathrm{OH}$ of the transferred strand and are subsequently used to attack target DNA (not shown) without prior liberation from the flanking donor DNA. Their transfer generates a forked molecule in which a donor and target strand are joined to the TE at each end and which provides a 3' OH in the flanking target DNA that can prime replication of the transposable elements (TE). This might be called target primed transposon replication. TE of the Tn3 and IS6 families transpose in this way. The second column shows a pathway adopted by the IS630 family. Here, the nontransferred strand is cleaved two bases within the TE (light green square) before cleavage of the transferred strand, which generates the $3^{\prime} \mathrm{OH}$. Repair of the donor molecule would lead to inclusion of a noncomplementary 2-bp scar or footprint (light green square). This is a cut-and-paste mechanism without TE replication. The third column represents transposition using a hairpin intermediate in which the transferred strand is first cleaved and the resulting $3^{\prime} \mathrm{OH}$ then attacks the opposite strand to form a hairpin at the TE ends liberating the TE from flanking donor DNA. This is then hydrolyzed to liberate the final transposition intermediate. This is a cut-and paste mechanism without TE replication. The fourth column shows a "copy out-paste" in mechanism adopted by a large number of IS families. It involves cleavage of one IS end and attack of the opposite end by the liberated 3 ' OH, the TE then undergoes replication using the $3^{\prime} \mathrm{OH}$ in the donor DNA, a process that might be called donor primed transposon replication. This generates a double-strand DNA transposon circle and regenerates the donor molecule. The circle then undergoes cleavage and insertion. Adapted from references $\underline{35}$ and 259 . doi:10.1128/microbiolspec.MDNA3 -0030-2014.f1 


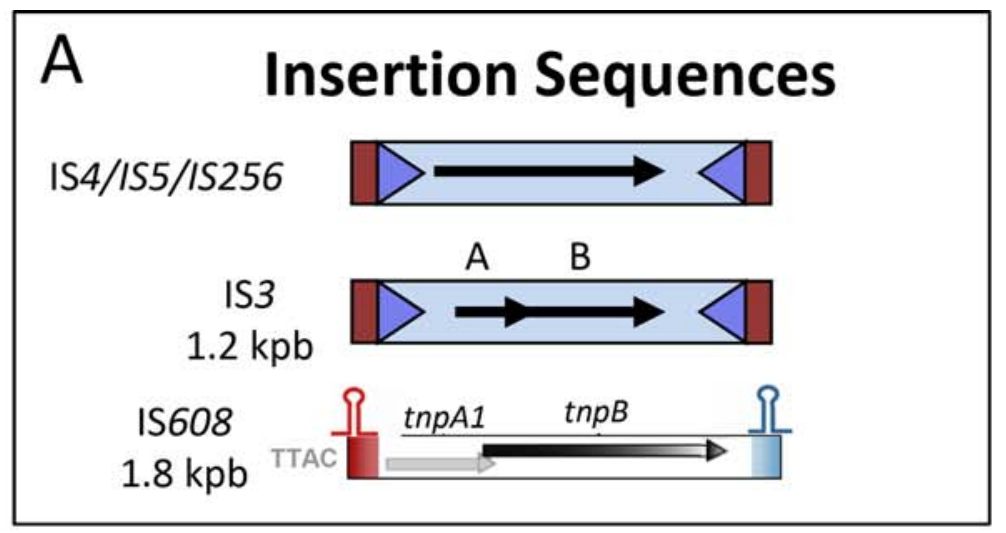

B Transposons

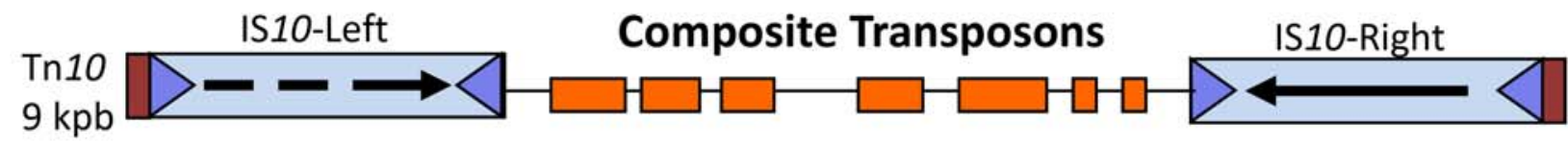

Unit Transposons

Tn3 family

$5->30 \mathrm{kpb}$

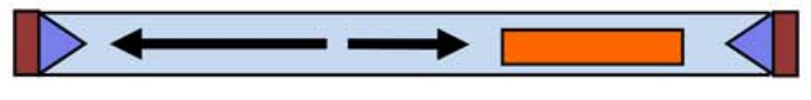

Integrative Conjugative elements (ICE)

Tn916
$18 \mathrm{kpb}$

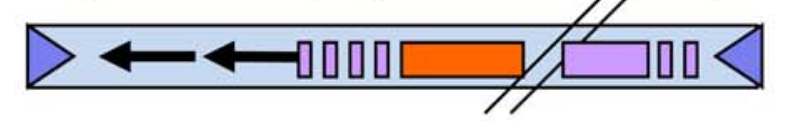

C MITEs, MICs and tIS

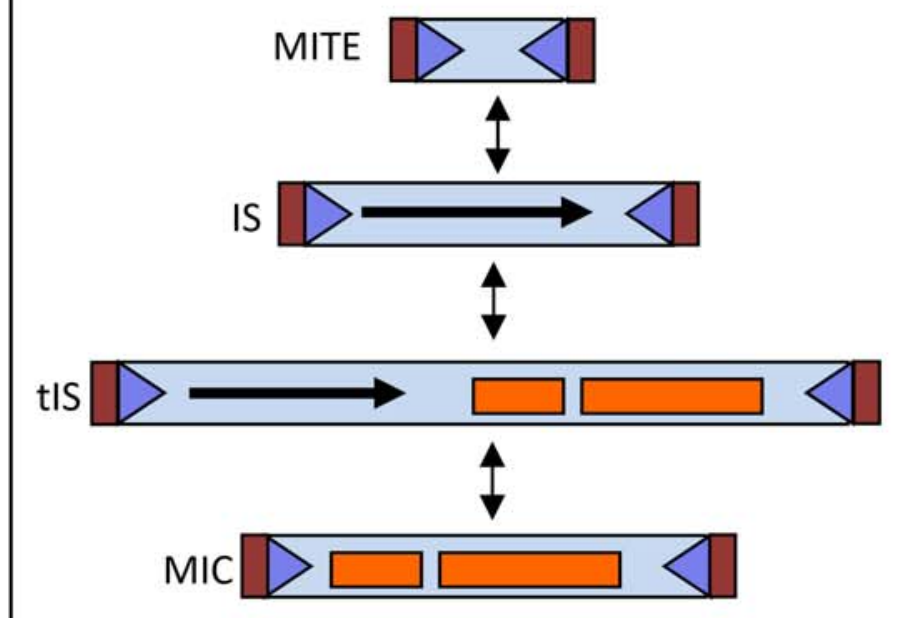

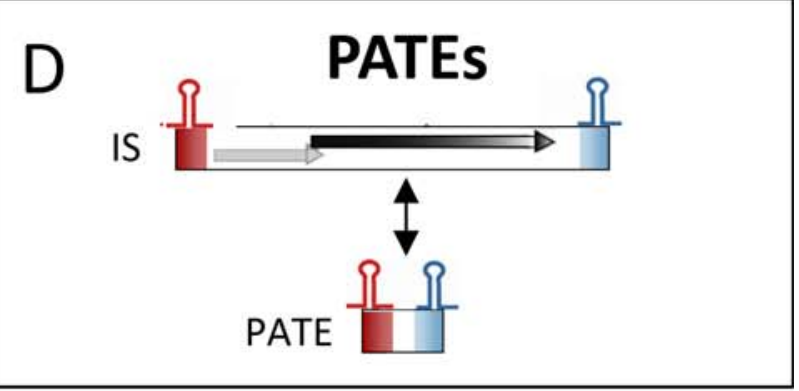




\section{IS91 and ISCR}

A final example of the subtle line dividing IS and transposons is found in the IS91/ISCR group. IS91 was identified some time ago (54) and carries a single Tpase orf. More recently, a group of related elements, ISCR (IS with a "common region") was described (reviewed in references 55 and 56). Although there has been no formal demonstration that these actually transpose, the CR is an orf that resembles the IS91 family HUH Tpases (41). The major feature of ISCR elements is that they are associated with a diverse variety of antibiotic resistance genes and, particularly in the case of Pseudomonas ISCR, with aromatic degradation pathways, both upstream and downstream of the Tpase orf. This is therefore another example of a very particular group of IS derivatives that appear to include multiple passenger genes.

\section{NON AUTONOMOUS IS DERIVATIVES}

Many prokaryotic genomes are littered with IS fragments and small, non autonomous IS derivatives whose transposition can, in principal, be catalyzed in trans by the Tpase of a related complete IS (Figure 2C). These miniature inverted repeat transposable elements (MITE) were first identified in plants $(\underline{57})$ and are related to IS with DDE Tpases. They are short $(\sim 300 \mathrm{bp})$, include terminal IR but no Tpase and generally generate flanking DR. Equivalent MITE-like structures called palindrome-associated transposable elements (PATE) (58) including the ends of IS200/IS605 family members (see IS families, below; He et al., this volume) with their subterminal secondary structures have also been identified (igure 2D). Both MITE and PATE probably derive from IS by internal deletion. The first MITE identified were related to eukaryotic Tc/mariner elements (distantly related to the bacterial IS630 family) and IS630related MITE were also the first described bacterial examples (59-61). MITE showing similarities to other IS families (e.g., IS1, IS4, IS5, IS6, and even Tn3 family members) have since been identified in bacteria and archaea $(62,63)$.

Another group of IS derivatives related to MITE are called mobile insertion cassettes (MICs) (64) (Figure 2C). These, like MITE, are flanked by IR, do not include a Tpase gene, and generate flanking DR. They carry various coding sequences, and are present in relatively low copy number. The IS231 subgroup of the large IS4 family includes examples of many of these IS-derivatives (canonical IS, MITE, MIC and tIS) (ㅎ5).

\section{RELATIONSHIP BETWEEN IS AND EUKARYOTIC TE}

In spite of their obvious similarities, there is often poor transfer of knowledge between studies of prokaryotic and eukaryotic TE. This artificial barrier is reflected in their nomenclature systems: Prokaryotic TE are named following the basic logic of bacterial genetics built on the initial Demerec rules (66); Eukaryotic TE, on the other hand, have more colorful names in keeping with the culture of nomenclature used in eukaryotic genetics. To a certain extent, this idiosyncratic nomenclature camouflages the diversity and relationships between members of the eukaryotic TE superfamilies and their prokaryotic cousins.

It is important to appreciate that the basic chemistry of transposition is identical for both prokaryotic and

FIGURE 2 Organization of different insertion sequence (IS) -related derivatives. IS with DDE transposases (Tpases) and their derivatives are shown as blue boxes, terminal inverted repeats as light blue triangles and flanking direct target repeats as red boxes. The Tpase orfs are shown as black horizontal arrows. Passenger genes are shown as orange boxes and transfer functions (in the case of ICE) are shown as purple boxes. The single-strand IS are indicated with their left (red) and right (blue) subterminal secondary structures indicated. (A) IS organization. From top to bottom: a typical IS with a single Tpase orf; an IS in which the Tpase reading frame is distributed over two reading phases and requires frameshifting for expression; and the organization of a typical member of the singlestrand IS family IS200/IS605. (B) Different IS-related TE. From top to bottom: composite transposon Tn10 with inverted flanking copies of IS10 (note that the left IS10 copy is not autonomously transposable); a unit transposon of the Tn3 family; and an integrative conjugative element (ICE). (C) Relationship between IS, miniature inverted repeat transposable elements (MITE), transporter IS (tIS) and mobile insertion cassettes (MIC). (D) Generation of palindrome-associated transposable elements (PATE) from IS200/IS605 family members. Adapted from references $\underline{20}$ and $\underline{43}$. doi:10.1128/microbiolspec.MDNA3 $-0030-2014.12$ 
eukaryotic elements (Hickman and Dyda, this volume). Moreover, many eukaryotic DNA transposons have similar sizes and organization to those of prokaryotic IS and, as most do not carry additional "passenger" genes, they are not transposons in the prokaryotic sense and should strictly be considered as eukaryotic IS. The major differences lie in how Tpase expression and activity are regulated (67). One important difference is that most eukaryotic transposons are "insulated" by constraints of the nucleus (which physically separate the transposition process from that of Tpase expression) whereas those of prokaryotes are not, because prokaryotic transcription and translation are coupled. In addition, eukaryotic transposons are subject to a hierarchy of regulation via small RNAs $(68,69)$. In prokaryotes, it is possible that CRISPRs (clustered regularly interspaced short palindromic repeats) may impose some control at this level but, although it has been demonstrated that CRISPRs are active against mobile genetic elements and may regulate some endogenous gene expression (70), these are limited to plasmids and phage and to our knowledge have not yet been demonstrated to act on intracellular MGE such as IS and transposons.

In spite of these differences, a significant number of eukaryotic DNA TE are related to prokaryotic IS, and moreover, eukaryotic TE including passenger genes are now being identified (71). This reinforces the view that the borders between different types of TE are "fuzzier" than previously recognized.

\section{IS IMPACT}

There is an increasing body of data describing the impact of IS on their host genomes. Although outside the scope of this review, it is important to provide a brief overview here because this is a crucial feature of IS.

\section{IS expansion, elimination and genome streamlining}

Perhaps one of the most spectacular characteristics of IS populations is their capacity to expand within genomes and also participate in genome streamlining or trimming by facilitating DNA deletion. There are many striking examples of IS expansion (20). These are often observed in bacteria with recently adopted host-restricted lifestyles. Current opinion is that the nutritionally rich environment of the host reduces the requirement for many genes that are essential for free-living bacteria, allowing fixation of slightly deleterious mutations in the population by random stochastic IS transposition and concomitant increase in IS copy number.
Additionally, IS activity may also eliminate genes responsible for surface antigens and interfere with regulatory circuitry, providing increased protection against host defenses $(\underline{72}, \underline{73})$. Fixation would be facilitated by successive population bottlenecks (74-77) and the effect would be more marked the more genetically isolated the bacterial population. Intracellular endosymbionts provide many examples of this. Accumulation of ISgenerated endosymbiont pseudogenes in functions that can be supplied by the host would increase the host dependence of the bacterial population $(\underline{78}-\underline{80})$. The capacity of IS to generate deletions would also be expected to eventually lead to complete or partial elimination of the IS themselves. This is thought to have occurred in the IS-free ancient endosymbionts. Genetic isolation of the population is key to the process of IS elimination because reinfection could occur by lateral gene transfer from other bacterial populations, a phenomenon that is thought to have occurred several times in certain Wolbachia sp. (1).

\section{IS and gene expression}

Another important aspect of IS impact on their bacterial hosts is their ability to modulate gene expression. In addition to acting as vectors for gene transmission from one replicon to another in the form composite transposons (two IS flanking any gene; Figure $2 \mathrm{~B}$ ) and tIS (Figure 2C) and their ability to interrupt genes, it has been known for some time that IS can also activate gene expression $(\underline{5}, \underline{82})$. This capacity has recently received much attention because of the increase in resistance to various antibacterials $(\underline{83}, \underline{84})$, a worrying public health threat (ㅁ5-87).

They can accomplish this in two ways: either by providing internal promoters whose transcripts escape into neighboring DNA $(\underline{82}, \underline{88})$ or by hybrid promoter formation. Many IS carry -35 promoter components oriented towards the flanking DNA. In a number of cases this plays an important part in their transposition because a significant number of IS transpose using an excised transposon circle (see Major IS groups are defined by the type of transposase they use section, above) with abutted left and right ends. For these IS, the other end carries a -10 element oriented inwards towards the Tpase gene. Together with the -35 , this generates a strong promoter on formation of the circle junction to drive the Tpase expression required for catalysis of integration (Chandler et al., this volume) (89-91). Hence, if integration occurs next to a resident -10 sequence, the IS -35 sequence can contribute to a hybrid promoter to drive expression of neighboring genes, see reference 92 . 
At present this phenomenon had been reported to occur with over 30 different IS in at least 17 bacterial species $(\underline{20}, \underline{93})$.

\section{Target choice}

The influence of different IS on genome architecture will depend not only on their levels of activity but also on the type of target into which they insert. It was initially believed that TE show no or only low sequence specificity in their target choice. For example IS630 and the eukaryotic Tc/mariner families (Tellier et al., this volume) both require a TA dinucleotide in the target $(\underline{36}, 37)$ whereas others such as the IS200/IS605 and IS91 families require short tetra- or penta-nucleotide sequences $(94,95)$. Yet others, such as IS1 and IS186 (of the IS4 family), show some regional specificity (for AT-rich and GC-rich sequences, respectively) (6-98).

Although, from a global genome perspective, insertion may appear to occur without significant sequence specificity, accumulation of more statistically robust data has uncovered rather subtler insertion patterns. For example, there is some indication from the public databases suggesting that IS density is generally significantly higher in conjugative bacterial plasmids than in their host chromosomes with the exception of special cases in which the host has undergone IS expansion as described above. Such plasmids are major vectors in lateral gene transfer providing good delivery systems for TE. Some TE, including IS, appear to be attracted to replication forks $(99,100)$ and show a strong orientation bias indicating strand preference at the fork (99101). Moreover, in certain cases, insertion may target stalled replication forks (He et al., this volume). A link between replication (in this case, replication origins) and insertion has also now been observed for a eukaryotic TE: the P element of Drosophila (102).

Some transposons such as Tn7 in Escherichia coli (103) and Tn917 in Bacillus subtilis (104), Enterococcus faecalis (105) and Streptococcus equi (but not in Listeria monocytogenes or Streptococcus suis) (106) also show a preference for integration into the replication terminus region and sites of DNA breakage may also attract insertions (103). It remains to be seen whether any IS has adopted these types of target preference.

Potential topological characteristics or secondary structures are another feature that can attract certain TE. Changes in topology induced by the nucleoid protein, H-NS, for example, may explain the effects of H-NS mutants on the target choice of IS903 and Tn10 (IS10) (107) (Haniford and Ellis, this volume). Members of the IS110, IS3, and IS4 families are examples of IS that insert into potential secondary structures such as repeated extragenic palindromes (He et al., this volume) (108-110), integrons (Escudero et al., this volume; 111, $112)$ or even the ends of other TE $(113,114)$.

In addition, IS21, IS30, and IS911 have all been observed to insert close to sequences that resemble their own IR (115-118). Although these IS are members of different families, they have in common the formation of a dsDNA excised circular transposon intermediate with abutted left and right ends (Chandler et al., this volume). Insertion next to a resident "target" IR such that IR of the IS are abutted "head-to-head" presumably reflects the capacity of the Tpase to form a synaptic complex between one IR present in the transposon circle and the target IR. This type of structure is extremely active in transposition and will continue to generate genome rearrangements.

Other factors that may be influential in determining target choice are interactions (direct or indirect) with DNA-associated host proteins. For example, Tn7 appears to be drawn to replication forks by interaction with the fork-associated $\beta$-clamp (119). Indeed, a recent large-scale analysis of IS insertions in bacterial chromosomes has pointed out the potential implication of sliding clamp in targeting and provided evidence for direct interaction of various transposases with the conserved replication processing factor $(\underline{120})$. A more detailed exploration of these results would be useful. Another potential interaction, in this case with RNA polymerase, is suggested by the recent observation that the transposon TnGBS (an ICE from Streptococcus agalactiae) and members of the closely related ISLre2 family insert preferentially 15-17 bp upstream of $\sigma \mathrm{A}$ promoters $(\underline{50}, \underline{51})$. Targeting of upstream regions of transcription units has also been extensively documented for certain eukaryotic transposons (121).

\section{Influence of transposition mechanisms}

The way in which strand cleavages and transfers occur during transposition also affects the outcome of the transposition events and therefore impinges on genome structure. For example Tn3 and IS6 family members, both with DDE Tpases, generate fusions or cointegrates between the donor and target replicons by a process of replicative transposition, presumably by target primed transposon replication (Hickman and Dyda, this volume) (Figure 1 first column). However, in the event of intramolecular transposition, this type of mechanism is expected to give rise to inversions with a copy of the IS at each junction or inversions with a single IS copy remaining and a second copy segregating with a circular- 
ized deletion (122). Note that similar effects are also known to occur by homologous recombination between two inverted or directly repeated IS copies in a replicon. Other known mechanisms such as cut-and-paste, or Copy out-Paste in (donor primed transposon replication) (34) would not generate this type of genomic rearrangement but could contribute to genomic modifications in other ways such as "nearly precise excision" $(123,124)$ or by using alternative sequences that resemble their IR $(\underline{125}, \underline{126})$.

\section{Summary}

The above considerations serve to provide an overview of the diversity of IS and their close TE relatives together with an outline of their behavior and its impact on prokaryotic genomes. Below we provide a guide to the present classification of IS and present a more detailed description of the individual IS families, their characteristics, differences, similarities, transposition mechanism (where known), and their distribution. There are clearly large disparities in our level of knowledge from family to family. Although we have tried to treat each family individually, we have grouped those that have proved to be related. We also include information concerning the identification of the different types of derivative elements such as MITES or tIS, which are related to given individual IS families.

\section{IS FAMILIES}

Insertion sequences in ISfinder are classified into families using a variety of characteristics (Table 1) (127) such as: transposition chemistry; length and sequence of the short imperfect terminal IR sequences (TIR in eukaryotes) carried by many IS at their ends; length and sequence of short flanking direct target DNA repeats; orf organization; and the nature of their target sequences. In many cases, these distinguishable differences are associated with different properties and behavior of the IS. An additional criterion is based on the presence/absence and order of various Tpase domains. Transposases are multidomain proteins. They include domains or modules involved in catalysis (e.g., DDE and HUH-see Major IS groups are defined by the type of transposase they use section, above), in sequence-specific binding to the TE ends (e.g., helix-turn-helix, HTH; zinc finger, ZF) and in multimerization (leucine zipper). The sequencespecific binding module is generally located in the Nterminal region permitting folding and binding of the nascent peptide before completion of translation (see IS3 and IS481 families section, below). In addition, they may include specific signatures for interaction with host proteins (Peters, this volume).

At present, IS in ISfinder are grouped into 29 families and many of these are further divided into subgroups based on shared characteristics. Although there are very well-defined homogeneous families (such as IS3, IS30, and IS256) others have been redefined over time as more and more IS are identified (e.g., IS4 and IS5).

It is important to note that the number of IS in a given ISfinder family does not necessarily reflect their relative abundance in nature. Some estimates of this have been made from time to time using different approaches, although the accuracy of these is difficult to assess $(74,128,129)$. IS inclusion in ISfinder has not involved a systematic global search of the public databases.

We emphasize that this is a description of the ISfinder classifications at this time and that some groups will certainly emerge with further additions to the database and more detailed analysis.

\section{IS WITH DDE TRANSPOSASES IS1 and IS1595: two related families}

IS1.

(i) General

IS1 was among the first bacterial insertion sequences to be identified (13). It is also one of the shortest (768 bp) and has been identified in over 40 different bacterial and archaeal species. IS1 is a component of several compound transposons $(12,130)$ where it is present in direct or inverted orientation. It is also found in several conjugative plasmids flanking large regions carrying a number of antibiotic resistance genes (resistance determinant or r-det) (131) and can participate in homologous recombination to generate circular $r$-det forms or tandem multimers resulting in increased antibiotic resistance (132).

\section{(ii) Organization}

The family has been extensively reviewed previously (26, 127) (and references therein). Integration generates a $9 \mathrm{bp}$ target DR but DR of 8,10 , and 14 bp also occasionally occur. The classic IS1 includes $23 \mathrm{bp}$ imperfect inverted repeats (IRL and IRR) and two partly overlapping orfs (ins $A$ and ins $B^{\prime}$ ) located in the 0 and -1 relative translational phases and expressed from a promoter partially located in IRL. Their integrity is essential for transposition. The insA product, InsA, binds both IR and regulates expression and probably transposition activity. The 
Tpase, InsAB', is a transframe fusion protein produced by programmed ribosomal frameshifting, between ins $A$ and ins $B$ ' with typical frameshift signals. Programmed ribosomal frameshifting occurs at a frequency of about $1 \%$. No InsB' protein species has been detected.

IS1-related derivatives carrying only a single orf have been identified. These tend to be longer $(\sim 1,000 \mathrm{bp})$ than the classic IS1 with slightly longer Tpases due to an $\mathrm{N}$-terminal extension (Table 1). They retain the characteristic IS1 IR sequences (Table 1). They were first observed in the archaeal Sulfolobiales (ISC1773 $a$ and $b$ and ISSto7) where this arrangement appears to be the rule (63) but are not restricted to the Archaea. Several examples occur in Eubacteria (e.g., ISAba3, Acinetobacter baumannii, and ISPa14, Pseudomonas aeruginosa) (43). It is possible, as in the case of $\operatorname{dnaX}(\underline{133})$, that the upstream N-terminal protein is indeed produced but by frameshifting to generate the smaller derivative from the full-length protein.

Overall transposition activity appears to depend on the ratio of InsA/InsAB', serving to regulate activation of transposition by uncontrolled Tpase expression from external transcription. It had been suggested that a translational restart within the ins $A$ frame giving rise to an InsAB' protein with an N-terminal deletion generates the true Tpase (134). However, although the importance of this protein cannot be ruled out, the establishment of an in vitro IS1 transposition system based on partially purified engineered InsAB' suggests that the translational restart product may not play a central role (135).

\section{(iii) Mechanism}

In vivo, direct visualization of 13 DNA species obtained following induction of IS1 transposition and the kinetics of their appearance and disappearance clearly identified forms corresponding to reciprocal products of ISmediated deletions as well as excised transposon circles. This suggests that IS1 can transpose using both the cointegrate (target primed transposon replication) and Copy out-Paste in (donor primed transposon replication) pathways (136).

\section{(iv) Transposase organization}

Alignment of InsAB' from different members of the family confirmed the presence of a C-terminal DDE catalytic domain (137) and also revealed potential N-terminal ZF and HTH motifs $(135,138)$. Addition of 1,10phenanthroline, which shows a high affinity for zinc, prevented binding to IS1 IR, as did mutations in either of the two motifs whereas mutation of the DDE motif confirmed its importance in catalysis but not in binding $(135,138)$. All three motifs are observed in the longer Tpases with a single long reading frame.

However, members of the ISMbu11 subgroup lack the N-terminal ZF while retaining the HTH motif (43). They include a 30-120-residue C-terminal extension that is unrelated in different members of this group and the spacing between the second $\mathrm{D}$ and $\mathrm{E}$ residues is 40-60 amino acids longer. Three different organizations of ISMbu11 subgroup members were identified: examples with two orfs and a potential frameshift zone (ISMbu11, ISMac25, ISArch18, and ISAcma3); a single example with additional noncoding DNA upstream of the Tpase orf (ISBeg1); and members that carry passenger genes (Table 1) generally with no known function, but often with other relatives in different bacteria. An exception is tISSce1, which includes orfs resembling a DNA methyltransferase, a possible sigma factor, and member of the HTH_XRE family of transcription regulators. However, only a single example of each type with passenger genes was identified, suggesting that these IS have low or no transposition activity.

More extensive comparisons have indicated that IS1 is distantly related to another relatively newly recognized family, IS1595.

\section{IS1595.}

\section{(i) General}

IS1595 was identified in Xanthomonas campestris (43) and closely related IS (e.g., ISXo2, ISXo5, ISXo16, and ISXca4) are present in high copy number in other Xanthomonas species. The IS1595 family is less homogeneous than the IS1 family. BLAST analysis of ISfinder using IS1595 as a query confirmed a distant relationship with IS1 family members and with IS1016 (139), a multicopy Neisseria element previously binned with the "unclassified" IS (ISNYC). Seven subgroups have been identified: IS1595, IS1016, ISPna2, the halobacterial ISH4 group (140), ISSod1, ISNwi1 and ISNha5. Members of the ISPna2, ISNwi1 and ISNha5 subgroups may contain passenger genes or additional noncoding DNA (43). As in the case of ISMbu11, only a single example of each member was identified, suggesting that these IS have low or no transposition activity. It is also related to ISSag10 from Streptococcus agalactiae. This was originally called MTnSag1 and thought to be a member of the IS1 family (141) but now called tISSag10 due to the presence of an O-lincosamide nucleotidyltransferase passenger gene. tISSag10 also carries an origin of transfer and can be mobilized by transfer functions of Tn916. It can therefore also be defined as a non autonomous 
ICE, again underlining the increasing difficulty in TE classification.

\section{(i) Organization}

Most are flanked by 8 bp AT-rich DR and have a single Tpase orf. Like IS1 family Tpases, they include an N-terminal ZF, an HTH motif, and a C-terminal catalytic motif with some exceptions. For example IS1016 group members lack the N-terminal ZF but, as IS1016 is present in multiple copies, it is probably active. The catalytic sites of all family members show group-specific variation particularly around the final $\mathrm{E}$ residue. More surprising is the apparent substitution of the final $\mathrm{E}$ residue for $\mathrm{N}$ or $\mathrm{H}$ in certain members. The exact nature of these possible noncanonical catalytic sites will require experimental determination.

It has been reported that the IS1595 family (in particular IS1016) is related to the Merlin family of eukaryotic TE (142), especially at the level of the DDE motif and the position of an upstream HTH. They also have comparable lengths and similar IR. The Merlin Tpase is longer at the $\mathrm{N}$-terminus than that of IS1016 and more similar in size to the other members of the IS1595 family although it does not exhibit the IS1595 N-terminal ZF.

\section{IS3 and IS481 families}

\section{IS3.}

\section{(i) General}

The IS3 family is one of the most coherent and largest IS families (143) (see Chandler et al., this volume). It is very widely distributed and at present ISfinder includes 554 different members from more than 270 bacterial species. The family is quite homogeneous in spite of its wide distribution in bacteria exhibiting a large range of $\mathrm{G}+\mathrm{C}$ contents and of the presence of members in hosts such as Mycoplasma with a nonuniversal genetic code (e.g., IS1138) or in bacteria that use stop codon read-through by insertion of the unusual amino acid selenocysteine (e.g., ISDvu3 from Desulfovibrio vulgaris). In the case of both copies of IS1138, which participates in highfrequency rearrangements of the Mycoplasma pulmonis chromosome, the Tpase orf carries 11 UGA codons, which are decoded as tryptophan (144).

Although most members had been limited to the eubacteria (63), an example, ISMco1, has now been identified in the Archaea Methanosaeta concilii. As this Archaea is widespread in nature (145), it is possible that this represents a case of recent horizontal transfer. The presence of eight copies implies that ISMco1 is active in its archaeal host.

\section{(ii) Organization}

Members carry relatively well conserved IR and invariably express their Tpases as fusion proteins using programmed -1 frameshifting. All have characteristic terminal IR generally terminating with the dinucleotide 5'-CA-3' and carrying a short block of GC-rich sequence. They generate 3 or $4 \mathrm{bp} \mathrm{DR}$ on insertion. Their Tpase, OrfAB, like those of the majority of IS1 family members, is expressed as a fusion protein by programmed - 1 programmed ribosomal frameshifting from two consecutive, partially overlapping reading frames with the second located in the -1 reading phase compared to the upstream frame (Chandler et al., this volume).

A clade carrying noncanonical ends has recently been identified. This is currently composed of 15 members. These IS include seven supplementary base pairs on each end flanking canonical IS3 ends: a conserved stretch of five $\mathrm{C}$ residues is located $5^{\prime}$ to the left IR and a less conserved motif (CGG) is located $3^{\prime}$ to the right end. When these additional bases are taken into account every member of this clade exhibits a 4 bp DR characteristic of the IS3 family (Table 1) (E. Gourbeyre, unpublished). This conclusion is supported by the presence of multiple IS copies (e.g., ISPsy31) and also by identification of "empty sites" (ISfinder). This clearly requires further experimental investigation.

Recently, an additional subgroup has been proposed, which includes ISPpy1 (146). However, all members belong to the IS150 subgroup and their Tpases are not separated by our standard multiple alignment and Markov Cluster Analysis (MCL) analysis. Although they do exhibit some variation in the sequence of their terminal dinucleotides, similar variations are found for IS2 and members of other IS3 subgroups.

\section{(iii) Mechanism}

IS3 family members transpose using a Copy out-Paste in, donor primed transposon replication, mechanism that produces dsDNA circular intermediates (Figure 1). The recognition sequences and cleavage points have been well characterized experimentally in several IS3 family members. In vitro transposition systems have been developed for several family members (Chandler et al., this volume). Bridged molecules are formed in an asymmetric manner by cleavage of one IS end to generate a $3^{\prime} \mathrm{OH}$, which then attacks the other end to generate a singlestrand bridge between the IS ends. A copy of the IS appears to be replicated out as a circle leaving the other IS copy in the reconstituted donor DNA replicon (Chandler et al., this volume). 
One member of this family, IS911, has been used to address the mechanism, common to many IS, in which the Tpase shows a preference for acting on the IS copy from which it was synthesized (cis activity). It was shown that this behavior depends on coupling between transcription and translation and results from co-translational binding of the nascent Tpase peptide to the IS ends (147).

\section{IS481}

Initially, IS481 appeared to be an IS3 family derivative that had been truncated for the N-terminal end of the Tpase and includes a C-terminal extension. The DDE active site domain and the IR (ending in $5^{\prime}$ TGT $3^{\prime}$ ) are similar to those of IS3 family members. Their presence in high copy number in some species and the identification of at least 130 distinct but related IS from over 90 species strongly suggests that these represent a distinct transpositionally active family. Different members generate DR of between 4 and $15 \mathrm{bp}$. Moreover, certain members (e.g., ISSav7) insert specifically into the tetranucleotide CTAG, which becomes the flanking DR and provides the UAG termination codon for the Tpase. In contrast to the vast majority of IS3 family members, the IS481 Tpase is not produced by frameshifting. There is no evidence for a leucine zipper as in IS3.

Some members include passenger genes including antibiotic resistance $\left(\mathrm{Cm}^{\mathrm{R}}\right.$ for IS5564 and ISCgl1), or potential transcriptional regulators (ISKrh1, ISPfr21, ISSav7). IS481 itself has played a fundamental role in the evolution of the genomes of the Bordetellae where, in Bordetella pertussis it has undergone extensive amplification to several hundred copies with accompanying genome decay $(\underline{72}, \underline{73})$.

These IS are distantly related to the eukaryotic Banshee transposon, which at present is restricted to the anaerobic flagellated protozoan Trichomonas vaginalis (Pritham per. comm.) (148). They share the highly conserved Pfam integrase core domain identified initially in the IS3 family and retroviruses $(\underline{28}, \underline{29})$. They also show a conserved $5^{\prime}$ TG $3^{\prime}$ tip to the IR, which is typical of this and other types of mobile element. It would be interesting to determine whether Banshee transposes using a dsDNA circular intermediate as do IS3 family members.

\section{IS1202 group (ISNCY)}

A small group including IS1202 (149), composed of 10 IS which had been included in the ISNCY (not classified yet) group appears distantly related to IS481. Members are between 1,400 and 1,700 bp (except for ISKpn21, which includes a passenger gene annotated as "hypothetical protein") with a Tpase orf of between 400 and 500 amino acids in a single reading frame. Their IR begin with TGT as do those of the IS3 and IS481 families. They generate DR of between 5 and, unusually, $27 \mathrm{bp}$.

They appear to have similarities at the level of their Tpases particularly in their DDE domains (e.g., IS1202 has $39 \%$ amino acid similarity to ISPfr 5 of the IS481 family). They include a glutamine (Q) seven residues $\mathrm{C}$-terminal to the conserved $\mathrm{E}$ instead of the characteristic K/R. Identification of additional IS will be necessary to clearly define this group.

\section{The redefined IS4 and related families}

The accumulation of additional related IS has permitted a more detailed analysis of the IS4 family, which had already become heterogeneous displaying extremely elevated levels of internal divergence (150). Based on more than 200 IS4-related sequences from bacterial and archaeal genome sequences, seven subgroups and three emerging families (IS701, ISH3, and IS1634) were defined. Separation into three emerging families was principally due to variations in an important conserved YREK motif, a division that is supported by the IR sequences and the associated DR.

Members of all these encode a Tpase with an insertion domain rich in $\beta$-strand and located between the second D and the E of the DDE motif (31). That of the IS50 Tpase (151) is the only example that has structural support (152), although bioinformatic analysis (31) indicated that ISH3 (e.g., ISC1359 and ISC1439), IS701 (e.g., IS701 and ISRso17; (153)) and IS1634 (e.g., IS1634, ISMac5, ISPlu4; (154)) family members also exhibit a similar insertion domain.

\section{IS4}

The IS4 family originally included a diverse collection of IS characterized by three conserved domains in the Tpase [N2, N3, and C1 containing D, D, and E respectively; (151)]. In addition to the conserved DDE triad, this family is defined by the presence of an additional tetrad YREK (150) which, in the case of IS50, is thought to be involved in coordination of a terminal phosphate group at the $5^{\prime}$ end of the cleaved IS (155) (Haniford and Ellis, this volume).

\section{IS701}

The IS701 family was distinguished from the IS4 family by a highly conserved 4 bp target duplication, 5'-YTAR$3^{\prime}$. MCL analysis also indicated that the Tpases form a 
defined and separate group and alignments indicated the absence of $\mathrm{Y}$ in the Tpase YREK motif. There are several clades within this family. A new clade, ISAba11, was proposed as a new family based on five IS (156). Members of this group generate 5 bp target duplications (instead of $4 \mathrm{bp}$ ), exhibit conserved IR and include HHEK instead of YREK. However, additional examples (ISfinder) exhibiting the conserved IR did not universally contain HHEK and MCL cluster analysis did not strongly support the notion that ISAba11 constitutes a new family. At present, we have retained ISAba11 as a subgroup in the IS701 family.

\section{ISH3}

The ISH3 family is restricted to the Archaea. In roughly half of the 30 members identified, the Tpase lacked the $\mathrm{K} / \mathrm{R}$ residue of the DDE motif whereas all except ISFac10 displayed a $\mathrm{Y}(2) \mathrm{R}(3) \mathrm{E}(3) \mathrm{R}$ motif. A characteristic of this family is the presence of $5 \mathrm{bp}$ DR flanked at one end by $\mathrm{A}$ and at the other by $\mathrm{T}$.

\section{IS1634}

The IS1634 family (previously IS1549) is characterized by large Tpases due to a $\beta$-strand insertion domain located between the conserved second $\mathrm{D}$ and $\mathrm{E}$ residues, which is 35 to 79 amino acids longer than that of IS4 and members of the other related families. They generate 5 bp to 6 bp AT-rich DR and are present in both Archaea and bacteria (150). Certain members generate very long variable DR (e.g., IS1634 from 17 to $478 \mathrm{bp}$, (154); ISCsa 8 from 16 to $131 \mathrm{bp}$; ISMhp1, $80 \mathrm{bp}$ ).

\section{The redefined IS5 and related IS1182 families}

Like the IS4 family, growth in the number of identified members of the IS5 (564 members) and IS1182 families (142 members) has revealed that the two are related and has allowed a more detailed analysis and a separation into various subgroups and families The IS5 family is now partitioned into six subgroups: IS5, IS903, ISL2, ISH1, IS1031, and IS427. Some of these may prove to be emerging families.

There is a distant relationship, about $30 \%$ similarity, with the Pif/Harbinger group of eukaryotic TE (148, 157).

\section{IS5}

Although the majority of members have a single Tpase orf, about $20 \%$ of family members may express Tpase by frameshifting because it is distributed between two translation phases similar to most of the IS427 subgroup $(82 / 116)(127)$. In these cases the frameshifting signals appear more appropriate for a programmed transcriptional realignment frameshift mechanism rather than for classical translation frameshifting (programmed ribosomal frameshifting) as there are no obvious downstream enhancement signals (21). Similar split reading frames have now been identified in several other subgroups: IS1031 (13/65 members); ISL2 (7/43); and few in the IS5 subgroup (7/149). There is no experimental evidence that these frameshift signals are functional but many of the IS are in multiple copies, suggesting that the derivatives are active. In view of their diversity compared with families such as IS3, the subgroups will certainly be partitioned into additional groups as more IS are identified. At present, the IS903 and the archaeal ISH1 subgroups do not contain members with potential frameshifting.

In addition to their Tpases and the presence or absence of potential frameshifting, a further distinction between these elements resides in their target specificities. Certain IS427 subgroup members and IS1182 family members do not carry a termination codon for their Tpases but generate this on insertion into a specific target sequence, CTAG, which is duplicated on insertion. Other IS such as IS1031, duplicate a sequence TNA while others such ISL2 appear to duplicate ANT.

\section{IS1182}

IS1182 family members exhibit a diverse set of target specificities. Some duplicate $4 \mathrm{bp}$. These are of two types: those specific for CTAG and those that show no apparent target sequence specificity. Yet others target palindromic sequences. These are also of different types: some insert at the $3^{\prime}$ foot of a stem-loop and duplicate the entire structure whereas others insert $3^{\prime}$ of the loop and simply duplicate the loop (P. Siguier, E. Gourbeyre and M. Chandler, unpublished).

\section{ISDol1 group (ISNCY)}

Another small group, ISDol1, with 17 members from 15 bacterial species has recently emerged from the ISNCY "orphan" group. Members have a length of between 1,600 and 1,900 bp and generate DR of 6-7 bp.

\section{IS6}

\section{(i) General}

There are at present 130 family members in ISfinder from nearly 80 bacterial and archaeal species but this represents only a fraction of those present in the public databases. The family was named after the directly repeated insertion sequences in transposon $\operatorname{Tn} 6(\underline{158})$ to standardize the various names that had been attributed 
to identical elements (e.g., IS15, IS26, IS46, IS140, IS160, IS176). Many are found as part of compound transposons (159-161) invariably as flanking direct repeats, a consequence of their transposition mechanism.

Recent activity resulting in horizontal dissemination is suggested by the observation that copies identical to Mycobacterium fortuitum IS6100 occur in other bacteria: as part of a plasmid-associated catabolic transposon carrying genes for nylon degradation in Arthrobacter sp. (162), from the Pseudomonas aeruginosa plasmid R1003 (164), and within the Xanthomonas campestris transposon $\operatorname{Tn} 5393 b$ (164).

One member, IS257, has played an important role in sequestering a variety of antibiotic resistance genes in clinical methicillin-resistant Staphylococcus aureus isolates. It provides an outward oriented promoter that drives expression of genes located proximal to the left end. Moreover, both left and right ends appear to carry a -35 promoter component, which would permit formation of hybrid promoters on insertion next to a resident -10 element (165).

A single member, ISDsp3, present in single copy in Dehalococcoides sp. BAV1 carries a passenger gene annotated as hypothetical protein.

IS6 family elements are abundant in Archaea and cover almost all of the traditionally recognized archaeal lineages (methanogens, halophiles, thermoacidophiles, and hyperthermophiles) (63).

They form a monophyletic group related to bacterial IS from Firmicutes but can be further divided into three phylogenetic groups present in the halophiles, the sulfolobales, and the pyrococcales/methanosarcinales. The IR of the archaeal IS6 members are variable compared with the bacterial members and generally terminate with 5'-GT or 5'-GA, as opposed to the 5'-GG found in bacteria. The large phylogenetic distribution of IS6 family members in the Archaea and the monophyly of the IS6 archaeal group suggest that these elements were ancestrally present in the Archaea rather than being recently acquired by lateral gene transfer from bacteria.

IS26 is encountered with increasing frequency in plasmids of clinical importance where it is involved in expression of antibiotic resistance genes and plasmid rearrangements $(\underline{166}-\underline{171})$.

\section{(ii) Organization}

The putative Tpases are very closely related and show identity levels ranging from 40 to $94 \%$. They generally range in length from $789 \mathrm{bp}$ (IS257) to $880 \mathrm{bp}$ (IS6100). However, a separate group represented by seven members are somewhat larger (approximately 1,200 bp) as a consequence of an N-terminal extension with a predicted ZF. Several members (e.g., ISRle39a, ISRle39b, and ISEnfa1) apparently require a frameshift for Tpase expression. It is at present unclear whether this is biologically relevant. However, alignment with similar sequences in the public databases suggests that ISEnfa1 itself has an insertion of 10 nucleotides and is therefore unlikely to be active.

All carry short related $(15-20 \mathrm{bp})$ terminal IR and generally create $8 \mathrm{bp} \mathrm{DR}$. A single orf is transcribed from a promoter at the left end and stretches across almost the entire IS. In the case of IS26 this is located within the first $82 \mathrm{bp}$ of the left end and the intact orf is required for transposition activity.

\section{(iii) Mechanism and insertion specificity}

The predicted amino acid sequence of the Tpase exhibits a strong DDE motif. Translation products of this frame have been demonstrated for several members (e.g., IS240). Little is known about Tpase expression although transposition activity of IS6100 in Streptomyces lividans is significantly increased when the element is placed downstream of a strong promoter.

Where analyzed, members of the IS6 family give rise exclusively to replicon fusions (cointegrates) in which the donor and target replicons are separated by two directly repeated IS copies (e.g., IS15D, IS26, IS257, IS1936) (172). Transposition of these elements therefore presumably occurs in a replicative manner by target primed transposon replication. No known specific resolvase system such as that found in Tn3-related elements has been identified in this family and it is assumed that cointegrate resolution occurs via homologous recombination. It is for this reason that compound IS6-based transposons carry directly repeated flanking IS copies. Recent results suggest that the IS6 family member IS26 may transpose in an unusual manner (173), an observation which merits further investigation.

No marked target selectivity has been observed.

\section{IS21}

\section{(i) General}

The IS21 family is fairly homogeneous. It has more than 140 members from about 80 bacterial species. IS21 was discovered in plasmid R68 where it was subsequently observed to undergo a tandem duplication, which greatly facilitated the insertion of the plasmid into the Pseudomonas host genome. This led to the formation of Hfr strains $(174,175)$ and the subsequent demonstration that the Pseudomonas chromosome was genetically circular (176). 


\section{(ii) Organization}

IS21 family members encode two genes, the Tpase ist $A$ and a "helper" gene, ist $B$, which exhibits some similarity to the DnaA replication initiator protein due to the presence of an ATP-binding motif, and often appears in BLAST searches of complete genomes. In many members, the termination codon of ist $A$ and the initiation codon of ist $B$ overlap, suggesting that IstB is produced by translational coupling. The IS 21 family terminal IR are complex and carry several tandem repeated sequences thought to be Tpase binding sites. Like a number of IS families, the ends of the element terminate with the dinucleotide 5'-CA-3'.

\section{(iii) Mechanism}

IS21 family members transpose using a two-step mechanism by formation of a reactive junction, similar to those formed in the copy-paste mechanism of IS3 and other families, in which two abutted IS21 ends are separated by several nucleotides. This is consistent with the marked tendency of IS 21 to insert in, or close to, an IS 21 end. The reactive junction is subsequently integrated into the target DNA to give a DR of 4 to $8 \mathrm{bp}$. Integration is optimal when the distance separating the two ends in the junction is $4 \mathrm{bp}$. It is efficient with a 2 or $3 \mathrm{bp}$ separation but inefficient with smaller or larger intervening sequences. IstA carries the DDE motif and is the Tpase. The molecular details of IstB activity are not known. Both Ist $A$ and IstB are required for efficient transposition whereas a product of an alternative translation initiation within the Tpase gene may facilitate integration. Using IstA-enriched Escherichia coli cell extracts, it was shown that this protein is responsible for $3^{\prime}$ end cleavage of IS21 and of both ends in the IR junction (177).

\section{IS30}

\section{(i) General}

The IS30 family currently comprises 94 members from over 70 bacterial species and an example, ISC1041, has also been found in the Archaea (178). IS30-like Tpases have also been found as integral parts of certain ICE from methicillin-resistant Staphylococcus aureus (53).

Members of this family are capable of activating neighboring genes by creation of a hybrid promoter on insertion next to a -10 promoter element $(\underline{83}, \underline{179-}$ 181).

\section{(ii) Organization}

IS30 family members have a single Tpase orf spanning almost their entire length. The Tpases show several well-conserved regions. One, in the $\mathrm{N}$-terminus includes a potential helix-turn-helix (HTH) motif, which, in the case of IS30, is responsible for IR binding $(182,183)$. Another in the C-terminal region contains the $\mathrm{DD}(33) \mathrm{E}$ motif. The terminal IR are between 20 and $30 \mathrm{bp}$ and contain some conserved sequence signatures (183), and their tips show significant sequence variation although in most of the elements the IR have not been experimentally confirmed. Insertion generally generates DR of $2-3$ bp but there are several exceptions in which the DR is between 12 and 32 bp (e.g., IS1630, IS1470, IS658, ISL7, ISLpl1) (183).

\section{(iii) Mechanism and insertion specificity}

The founding member of the family, IS30, is the best characterized at the mechanistic level $(117,182-189)$ and an in vitro transposition system has been developed (190). This 1,221 bp long Escherichia coli element belongs to a growing class of IS known to transpose through an intermediate formed by abutting the IR, donor primed transposon replication. Here the IR are separated by 2 bp $(179,184, \underline{186})$. Such an IR junction can be created by formation of a dimer of two directly repeated IS copies or by the formation of transposon circles. Both IS minicircles and dimers have been observed. IR-IR junctions have also been detected in some other IS30 family members such as IS18 (181), IS4351 (191), and IS1470 (193). A structure in which two IS30 ends are linked by a single-strand bridge (forming a figure of eight structure on a circular plasmid, has been identified (190).

IS30 also shows a preference for two distinct types of target sequence: "natural" hot spots, characterized by a 24 bp symmetric consensus, and, like many IS which transpose via a circular dsDNA intermediate, the IR of the element itself. A similar type of insertion specificity was observed for IS1655 from Neisseria meningitidis (189).

\section{IS66}

\section{(i) General}

IS66 was first identified in the Ti plasmid pTi66 of Agrobacterium tumefaciens (193). The vast majority of IS66 members originate from the Proteobacteria with several from the Bacteriodetes/Chlorobi and the Firmicutes. A second group of closely related IS, widely spread among both bacteria and Archaea are thought to represent a subgroup within the IS66 family (194). The founder member, ISBst12, originally isolated from Bacillus stearothermophilus, was described as a novel family (195), but identification of many additional examples suggests that the ISBst12 and IS66 groups should 
be considered a single family. ISBst 12 are found in Actinobacteria, Cyanobacteria, Deinococcus/Thermus, Firmicutes, and Planctomycetes as well as in Proteobacteria. They are also found in the Euryarchaeota phylum of Archaea (but have not yet been identified in the Crenarchaeota).

\section{(ii) Organization}

The IS66 reference copy from a plasmid of the enteropathogenic Escherichia coli B171, IS679, (196) is defined by three orfs: $\operatorname{tn} p \mathrm{~A}, \operatorname{tn} p \mathrm{~B}$, and $\operatorname{tn} p \mathrm{C}$ and relatively well conserved terminal IR of about 20-30 bp flanked by an $8 \mathrm{bp} \mathrm{DR}$ at their insertion sites. Orf tnpC is $1,572 \mathrm{bp}$ and its predicted product includes a typical DDE motif. It also carries an insertion domain between the second $\mathrm{D}$ and the E of the DDE motif (e.g., IS679, ISPsy5, and ISMac8) (31)

The role of the products of $\operatorname{tn} p A(651 \mathrm{bp})$ and $\operatorname{tn} p B$ (345 bp) is less clear. Mutation of each orf separately (by introduction of an in-frame deletion) reduced transposition by at least two orders of magnitude (196). The three frames are disposed in a pattern suggesting translational coupling: $\operatorname{tn} p B$ is in general in translational reading frame -1 compared with $\operatorname{tn} p A$ and in most cases the termination codon of $\operatorname{tn} p A$ and the initiation codon of $t n p B$ overlap (ATGA). An initiation codon for $t n p C$ occurs slightly downstream separated from $\operatorname{tn} p B$ by about 20 bp.

However, rather surprisingly, in the light of a requirement for all three orfs for transposition of the canonical IS66 family member IS679, members of the ISBst12 group are devoid of $\operatorname{tn} p A$ and $\operatorname{tn} p B$ and carry only the $\operatorname{tn} p C$ reading frame. Although both ISBst 12 and IS66 members contain IR, which start with 5'-GTAA-3', they are clearly distinguishable due to a single conserved A at bp 11 In ISBst12, which is not conserved in IS66.

IS66 members can be grouped into three classes based on their organization: those including all three orfs, A, B, and $\mathrm{C}$ transcribed in the same direction; those with additional passenger genes invariably present downstream of orfC and transcribed in the same direction; and those which lack orfA but retain both orfs B and C. Each of these organizations includes members with multiple copies, implying that they are active in transposition. In addition to the DDE catalytic domain (194), TnpC also exhibits a highly conserved CwAH-rR motif downstream of the second $\mathrm{D}$ residue, a relatively conserved CX2(C)X33CX2C motif characteristic of a ZF further upstream and a leucine-rich region which might form a leucine zipper necessary in multimerization of other Tpases (197), at the N-terminus. (iii) Mechanism and insertion specificity

Nothing is known about the transposition mechanism of this group of IS and they exhibit no substantial target sequence specificity.

\section{The IS256 cluster}

Recently, a study of ICE elements identified examples from type B Streptococcus (TnGBS) (50) and Mycoplasma (199) that include a DDE type Tpase rather than the more common phage integrase-like gene. Using a cascade PSI-Blast approach not only revealed two new IS families (ISLre2 and ISKra4) but established a distant relationship with the IS256 and ISH6 families (52).

Analysis of the N-terminal Tpase region (52) also identified two shared domains (N1 and N2). N2 corresponds to a potential HTH domain in the region of the IS256 Tpase, which recognizes the terminal IR (199).

The cluster can be divided into five clades containing nine groups based on branching of the Tpases phylogenetic tree: two types of closely related TnGBS, TnGBS1, and TnGBS2, and ISLre2 (MULT3); the mycoplasma ICE; IS256 (MULT1); ISH6 (MULT2); ISAzba1, ISMich2, ISKra4 (MULT4) (52).

There is a distant relationship with the Tpase of the eukaryotic Mutator TE and, like MuDR from Zea mays, many generate $8 \mathrm{bp}$ to $9 \mathrm{bp}$ target repeat on insertion. They have therefore been called MULE (for Mutatorlike Elements). Like MuDr/Foldback, members of these groups carry a largely $\alpha$-helical insertion domain (31) between the second $\mathrm{D}$ and $\mathrm{E}$ catalytic residues. This includes a conserved $\mathrm{C} / \mathrm{D}(2) \mathrm{H}$ signature present in the eukaryotic and prokaryotic IS $(\underline{52}, \underline{200})$.

\section{IS256}

The IS256 family can be subdivided into three groups: IS256, IS1249, and ISC1250. The classical IS256 group has more than 180 members in both bacteria and Archaea. They are between 1,200 and 1,500 bp long with IR of 20-30 bp and generate DR of between 8 and $9 \mathrm{bp}$.

IS256 itself was originally isolated as a component of the compound transposon Tn4001 (201, 202). This family is quite homogeneous. Members carry related IR of between 24 and $41 \mathrm{bp}$, and most generate 8-9 bp duplications. A single long orf carrying a potential DDE motif with a spacing of 112 residues between the second $\mathrm{D}$ and $\mathrm{E}$ residues, together with a correctly placed K/R residue. The catalytic residues have been validated by mutagenesis $(203)$. It was shown several years ago that the Tpase of IS256 family elements shares some similarities with the eukaryotic Mutator element (204), a 
relationship that has been explored recently in more detail (205).

Members of this family transpose using an excised circular dsDNA transposon intermediate (203, 206).

\section{IS1249 group}

There are more than 30 members confined at present to the actinobacteria and the firmicutes. They are about $1,300 \mathrm{bp}$ in length with IR of about $26 \mathrm{bp}$ and generally generate DR of $8 \mathrm{bp}$ (with variations of between 0 and $10)$.

\section{ISC1250 group}

At present there are only three members of this family in ISfinder. All are found in the Archaea Sulfolobus solfataricus.

\section{ISH6}

This group (MULT2) was originally observed uniquely in Archaea (63). There are 11 members of about 1,450 bp with highly conserved IR of 24-27 bp, DR of 8 bp and a single Tpase orf encoding a protein of $450 \mathrm{bp}$.

\section{ISLre2}

There are 48 entries for ISLre2 family members in ISfinder. They are restricted at present to the bacteria. They are between 1,500 and 2,000 bp long, with IR from 15 to $29 \mathrm{bp}$ and generate $9 \mathrm{bp}$ DR. Together with the related TnGBS ICE, show strong target specificity and insert 13-17 bp upstream of $\sigma \mathrm{A}$ promoters $(\underline{50}, 52)$ in oriented fashion with the right IS end (RE) proximal. PCR analysis has detected a transposon circle junction, as with the related ICE, suggesting that transposition may occur via a donor primed transposon replication process.

\section{ISKra4}

This new family includes 83 members and is divided into three related groups: ISAzba1, ISMich2, and ISKra4.

\section{(i) ISAzba1}

There are presently 28 members of this group. They encode a Tpase of between 450 and 480 amino acids, are 1,400 to $2,900 \mathrm{bp}$ long with IR of about $20 \mathrm{bp}$ and no DR. Six (ISAfe13, ISCot1, ISEc51, ISKpn19, ISSysp7) carry an orf in addition to the Tpase and this specifies a protein related to serine-recombinases or resolvases. Four of these also include a third orf annotated as hypothetical protein. The fifth, ISAfe13, carries the Tpase, a resolvase and an alternative orf annotated as ORF-3like from plasmid pRiA4b. Other proteins found in this family are annotated as being hypothetical or putative TnpR resolvases although no direct evidence for resolvase function is available. Eight other members simply encode the Tpase and the ORF-3 like protein. While ISCep1 includes the ORF-3-like protein and a third annotated as phage integrase or $x e r \mathrm{C} / \mathrm{D}$.

\section{(ii) ISMich2}

This includes 24 members which are presently limited to the cyanobacteria. Twenty-two have a Tpase orf distributed between two reading phases whereas in the remaining two the Tpase forms a unique continuous orf. However, all show a potential but atypical frameshift motif, TTTTTT which could be involved in either programmed ribosomal frameshifting or programmed transcriptional realignment recoding. Further experimental analysis would be necessary to confirm or refute this. Members are between 1,250 and 1,400 bp long with a Tpase of 360 amino acids, IR of between 18 and $39 \mathrm{bp}$ with 8 bp DR. Three members (ISCysp26, ISMic1, and ISMich2) carry a passenger gene annotated as hypothetical protein.

\section{(iii) ISKra4}

The 31 elements in this group range in size from 1,400 to $3,700 \mathrm{bp}$ due to the presence in some of various passenger genes. They have IR of 18 to $31 \mathrm{bp}$ and generate DR of $9 \mathrm{bp}$. Three carry passenger genes: ISL $d r 1$, a hypothetical protein and a reverse transcriptase; ISSri1, a transcriptional regulator; and ISTni1, a hypothetical protein. Six members may express their Tpases by frameshifting (five include a 7A motif and one with a motif, 5TC).

\section{IS630}

\section{(i) General}

There are over 160 members from over 80 bacterial and archaeal genomes.

\section{(ii) Organization}

Members are between 1,100 and 1,200 bp long with terminal IR and generally include a single orf. However, in about 90 members, the Tpase orf is distributed over two reading frames, suggesting that it may be produced as a fusion protein by frameshifting.

(iii) Mechanism

IS630 transposition has been addressed in vitro (207) using ISY100 (ISTcSa) first identified in Synechocystis sp. PCC6803 (208). The Tpase was shown to specifically bind ISY100 IR using an N-terminal domain containing 
two potential HTH motifs. It is the only protein required for ISY100 excision and integration and introduces double-strand breaks on mini-ISY100 on a supercoiled DNA substrate. Tc1/mariner element transposition has also been extensively studied in vitro (37) and a Tpase structural model is available $(209,210)$. IS630 Tpase cleaves exactly at the $3^{\prime}$ (transferred strand) IS ends and two nucleotides inside the $5^{\prime}$ (nontransferred strand) ends. Cleavage is less precise on linear substrates. Both single-end and, less frequently, double-end insertion occur in vitro in a TA-target-specific manner (208). Transposition does not involve a hairpin intermediate.

\section{(iv) Insertion specificity}

Family members show high target specificity inserting into and duplicating a TA dinucleotide with a preference for the sequence 5'-NTAN-3' (211). As the cleavages of the nontransferred strand occur 2 nucleotides within the 5 ' end of the IS, repair of the donor molecule after excision of the IS can result in a $2 \mathrm{bp}$ scar at the excision site.

The IS630 family is related to the Tc1/mariner family of eukaryotic TE particularly at the level of the DDE signature. There is also an N-terminal HTH motif. Moreover, IS630 and the Tc1/mariner families target similar sequences, have similar DR and transposition of both involves cleavage of two nucleotides inside the 5 ' ends (37).

\section{IS982}

\section{(i) General}

The IS982 family has nearly 100 entries in ISfinder from over 40 bacterial and archaeal species. In the case of ISLpl4 from Lactobacillus plantarum, identical copies have been detected in Leuconostoc mesenteroides, Oenococcus oeni, and Lactobacillus sakei indicating horizontal gene transfer. At least two members, IS982B $(\underline{212})$ and IS1187 $(\underline{83}, \underline{213}, \underline{214})$ can provide a -35 hexamer in their right IR capable of forming a hybrid promoter with a resident -10 and activating neighboring genes.

\section{(ii) Organization}

IS982 family members are between 962 and 1,155 bp long and carry similar terminal IR of between 18 and $35 \mathrm{bp}$ with conserved ends: 5'-ACCC-3'. They encode a single orf of between of 271 and 313 amino acids with a possible DDE motif but without a convincing conserved downstream $\mathrm{K} / \mathrm{R}$ residue. Little is known about the transposition of these elements. They generate DR of 6 to $8 \mathrm{bp}$.
Although the Tpase of a majority of members occupies a single reading phase, there are several examples in which the gene is distributed over two phases. It has been reported that $\mathrm{a}+1$ nucleotide insertion in the Tpase orf of an ISLpl4 from Oenococcus oeni may undergo programmed translational frameshifting at a low rate $(215)$. Although this must be confirmed, it would represent the first functional case of +1 frameshifting in IS. The Tpase of archaeal element ISPfu3 is also distributed over two phases. ISPfu3 carries a potential transcriptional frameshift signal A7 (programmed transcriptional realignment) present in all five copies suggesting that ISPfu 3 is active.

\section{IS1380}

This family is represented by 153 members from nearly 100 bacterial species in ISfinder. They show conserved ends terminating with $\mathrm{CCt} / \mathrm{c}$. Although the majority of their Tpases often include the canonical $\mathrm{DDE}(6) \mathrm{K} / \mathrm{R}$, several members exhibit other residues in place of the $\mathrm{K} / \mathrm{R}$. These include DDE(6)Q or DDE(6)I. A subgroup, IS942, composed of 13 members all restricted to Bacteriodetes, include DDE(6)N. None of these differences appear to affect the predicted secondary structure. In addition, to the host-restricted IS942 group, two other branches of the Tpase tree are restricted to the Actinobacteria. A single, poorly characterized NCBI database entry (WP_018034290) probably corresponds to an archaeal IS1380 member and intriguingly, an orf (XP_002337507) with a $100 \%$ match to ISLsp5 (Leptospirillum sp.) has been identified in the genomic sequence of the black cottonwood tree, Populus trichocarpa. Tpases of this family include an insertion domain with a predominantly $\beta$-strand secondary structure (31).

IS1380 itself (216) is present in high copy number in the Acetobacter pasteurianus NCI1380 genome and in several strains of acetic acid bacteria. At present the family contains two tIS present in a single copy: ISMsm12 (Mycobacterium smegmatis; tetR + methyltransferase) and ISRop1 (Rhodococcus opacus; reverse transcriptase).

This IS family is distantly related to the eukaryotic PiggyBac TE family (see Yusa, this volume) which also includes an insertion domain largely in the form of $\beta$-strand (148).

\section{ISAs1}

There are over 80 entries for this family in ISfinder from over 50 bacterial species. There are currently no archaeal members. ISAs1 family members are between 1,200 and 
$1,326 \mathrm{bp}$ long and generally carry terminal IR of between 14 and $22 \mathrm{bp}$. A single orf of between 294 and 376 amino acids occupies almost the entire length. There are several conserved $\mathrm{D}$ and $\mathrm{E}$ residues. The putative Tpase of IS1358 has been visualized using a phage T7 promoter-driven gene and that of ISAs1 has been detected in Escherichia coli minicells. The family also includes "H-repeats", which form part of several socalled rearrangement hot spots (RHS) elements containing another repeated sequence, the H-rpt element (Hinc repeat). H-rpt display features of typical insertion sequences although no transposition activity has yet been detected. For the sake of clarity, the H-rpt DNA sequences B (RhsB), C1 to C3 (RhsC), E (RhsE), and min.5 as well as H-rptF were renamed ISEc1 to ISEc7, respectively (127). The Tpases of this family include a $\beta$-strand insertion domain (31).

Little is known about the transposition properties of this family of elements. However, recent experiments with the Vibrio cholerae element IS1358 have demonstrated that insertion generates $10 \mathrm{bp} \mathrm{DR}$ and that, in Escherichia coli, it undergoes simple insertion into a target plasmid, pOX38 (217).

\section{ISL3}

\section{(i) General}

There are more than 120 members from nearly 80 bacterial species. The family also includes archaeal members, particularly in the Methanomicrobia. A potential tIS derivative that includes a mercury-resistance operon has also been identified in a conjugative plasmid in Enterococcus faecium (218).

\section{(ii) Organization}

Members range in size from $1,186 \mathrm{bp}$ to $1,553 \mathrm{bp}$, carry closely related IR of between 15 and 39 bp and generate DR of $8 \mathrm{bp}$. They generally have a single orf of between 400 and 440 amino acids, which shows good alignment and includes an $\alpha$-helical insertion domain (31).

However, IS1096 harbors two orfs: the upstream orf exhibits similarities to the ISL3 family Tpases; the second, $\operatorname{tn} p \mathrm{R}$, a MerR-like transcription factor, is related to orfs from Agrobacterium rhizogenes and Rhizobium sp. plasmids. TnpR appears to regulate transposition activity of ISPpu12 (219).

In IS1167, the reading frame appears to be distributed between two consecutive orfs with a potential for translational coupling suggested by overlapping initiation and termination codons (ATGA). Small sequences (130 to $340 \mathrm{bp}$ ) related to the IR of IS1167 have been detected in Streptococcus sanguis, Streptococcus pneumoniae, and Streptococcus agalactiae $(3,417)$.

\section{(iii) Mechanism}

Transposition of most of these elements has been demonstrated, but no detailed analysis of their transposition mechanism has yet appeared. IS1411 from Pseudomonas putida forms a circular species with abutted IR separated by 5 bp (220). Transposon circles are also formed by ISPst 9 (221) and an isoform of ISPpu12 (219) and IS31831 forms DNA species with a size expected for an excised transposon (222). There is some evidence indicating that transposition of these IS can be induced by a form of zygotic induction following conjugative transfer (219).

No obvious target sequence specificity has yet been observed although there is some suggestion that there may be a preference for AT-rich regions.

\section{Tn3}

\section{(i) General}

This represents a large and highly homogeneous group in terms of their transposition enzymes and terminal IR (Nicolas et al., this volume). Many are complicated in structure and include multiple antibiotic resistances, virulence and other "accessory" genes. These are often carried by another type of transposable element, integron cassettes (45). The Tn3 family is included here because certain family members resemble IS (e.g., IS1071, IS101, ISXc4/ISXc5) encoding only the Tpase flanked by IR.

\section{(ii) Organization}

The IR are generally 38 bp long, start with the sequence GGGG (occasionally GAGG) and terminate internally with TAAG. The Tn3 family encodes large (>900 amino acids) DDE Tpases with an $\alpha$-helical insertion domain (31). Classical Tn3 family members also encode a sitespecific recombinase. The major differences between members of this family are in the number and location of the many passenger genes and in the type of site-specific recombinase present.

\section{(iii) Mechanism}

The replicative transposition mechanism of this family involves formation of a cointegrate in which donor and recipient replicons are fused and separated at each junction with a directly repeated transposon copy (223). These structures must be "resolved", by recombination between the two transposon copies, to generate the donor and target replicons each retaining a single transposon 
copy. This is accomplished by a site-specific recombinase (resolvase), which acts at a unique DNA sequence, the Res site. Apart from passenger genes, the major difference between various Tn3-like elements is the nature of their resolvases (Nicolas et al., this volume).

\section{ISAz013}

This family, represented by 37 members in ISfinder, emerged from the ISNCY orphan group. It is based on both Tpase and IR sequence similarities. Insertion generates a $3 \mathrm{bp}$ AT-rich DR and the ends have a consensus GGa/g. Their Tpases are highly conserved with a probable DDE motif and an HTH motif at the N-terminus, which could function as a DNA binding domain. Two members encode two orfs with a possible programmed ribosomal frameshifting motif of 8 or $9 \AA$ while the other members encode a unique orf which includes a triple lysine at the equivalent position (E. Gourbeyre unpublished).

\section{IS WITH DEDD TRANSPOSASES IS110}

\section{(i) General}

At present, only a single IS family, IS110, is known to encode this type of DEDD enzyme, related to the RuvC Holliday junction resolvase (40). There are over 250 examples from nearly 130 bacterial and archaeal species.

The Tpase is closely related to the Piv and MooV invertases from Moraxella lacunata/Moraxella bovis (224, 225) and Neisseria gonorrhoeae (39, 226). Piv catalyzes inversion of a DNA segment permitting expression of a type IV pilin. However, the organization of IS110 family members and the inversion systems are different. In the inversion systems, the recombinase is located outside the invertible segment, whereas it is located within the IS element (수).

The family includes two subgroups. It has been suggested that these may even represent two distinct families (114, 227): IS110 and IS1111. Although their Tpases are very similar to those of the classical IS110, members of the second subgroup, IS1111, are distinguished from those of the IS110 group principally by the presence of small (7 to $17 \mathrm{bp}$ ) subterminal IR. This would be the only family that is not defined by differences in the Tpase but by the nature of the IS ends.

However, the entire group of IS exhibit significant differences: some have subterminal IR whereas others do not; some appear to generate small DR while others do not; and the entire family show significant variations in their target preferences.

\section{(ii) Organization}

The organization of IS110 family members is quite different from that of the DDE IS: they do not contain the typical terminal IR of the DDE IS and do not generally generate flanking target DR on insertion. This implies that their transposition occurs using a different mechanism to the DDE IS. They encode a single Tpase gene that spans the entire length of the IS. One characteristic which distinguishes IS110 family members from all other elements whose Tpases exhibit a predicted RNase fold is that the predicted catalytic domain of their DEDD Tpases is located N-terminal to the DNA-binding domain $(29,228)$. In the DDE Tpases it is generally located upstream.

\section{(iii) Mechanism}

It has proved difficult to determine the activity of these Tpases in detail in vitro. Transposition of IS with DEDD Tpases may be unusual and involve $\mathrm{HJ}$ intermediates, which must be resolved using a RuvC-like mechanism. This type of recombination would be consistent with the close relationship between DEDD Tpases and the Piv/MooV invertases, which presumably resolve $\mathrm{HJ}$ structures during inversion (229). The difference in domain organization between the DEDD and DDE Tpases reinforces the idea that the two IS types possess a different transposition mechanism.

Members of this family produce double-strand circular transposon intermediates (e.g., IS492:(90), (230); ISPa11 (114); ISEc11, (231); IS117 (232, 233); IS1383 (234)). However, it remains to be determined whether they use a copy-paste mechanism or whether the circular intermediate is formed by excision. For example, IS492 was identified within the extracellular polysaccharide production (eps) gene of Pseudoalteromonas atlantica (90, 235). IS492 clearly undergoes Tpase-dependent precise excision to regenerate a functional eps gene. Like many other IS that use double-strand circular intermediate, circle formation results in the assembly of a junction promoter from a -35 promoter element in the right end oriented outwards and a -10 promoter element in the left end oriented inwards $(\underline{90})$. In the case of IS1383, the -10 component of the promoter appears to lie within the DNA sequence located between the abutted IS ends. This promoter presumably serves to drive Tpase expression for the final integration step $(90,234)$. For IS1383, amplification of a putative circle junction suggested that the abutted IS ends were separated by $10 \mathrm{bp}$ composed of the $5 \mathrm{bp}$ flanking each end in the original target site. For IS492, this is distance is $5 \mathrm{bp}$. The IS492 copy within the eps gene is flanked by a 5-bp 
DR that is required for Tpase-dependent precise excision and for transposition of the IS (미).

\section{(iv) Insertion specificity}

Another characteristic of the IS110 family is their particular insertion specificities. IS492, ISPtu2, and ISSpi5 recognize a 7 bp sequence, 5'-CTTGTTA-3', and duplicate the first 5 bp (CTTGT). Excision of the IS regenerates the original target sequence (236). In the case of IS492, the flanking 5 bp were also essential for formation of the dsDNA circular form (90).

At least six different members of the IS1111 subgroup (ISKpn4, ISPa21, ISPst6, ISUnCu1, ISAzvi12, and ISPa25) show a preference for attC sequences of integrons (111) whereas others appear to prefer repeated extragenic palindrome (REP) sequences (109). Both targets are capable of assuming hairpin-like secondary structures. The integron $a t t C$ is central to integration of circular integron cassettes $(\underline{45})$ whereas REP sequences are small repeated extragenic palindromic sequences often present in many hundreds of copies in bacterial genomes and which play a variety of structural and regulatory roles (He et al., this volume). There are at least seven examples (IS621, ISPa11, ISPpu9, ISPpu10, ISRm19, ISPsy7, and IS1594) from both the classical IS110 and IS1111 groups, which have been identified as insertions into REP sequences. These are two types of insertion. In type 1, the IS inserts at the same position in the REP whereas type 2 insertions occur adjacent to a REP. Only one IS1111 member, ISPsy7, has been identified with type 2 insertion specificity (109). Certain IS that insert into REP (e.g., IS621, ISPpu9, ISPpu10 and IS1594) generate a duplication of $2 \mathrm{bp}$.

Other IS of this family also appear to insert into conserved target sequences: IS1533 occurs in 84 copies in Leptospira borgpetersenii and inserts into a partially conserved sequence (ttAGACAAAA[IS1533]TATCAG agcc-gtct-aaa); ISRfsp2 from Roseiflexus sp. RS-1, present in 40 copies in the host genome, is flanked by the sequence, CTCtGCGaaCGCtGCGc[ISR $f s p 2]$ CTCtGCG Gtg. Yet other IS of this family appear to target the ends of other IS. Hence IS1383 present in six copies in Pseudomonas putida plasmids, inserts into the sequence TTCAGATGGT[IS1383]ATAAG contained within the end of another IS of the IS5 family, IS1384 (227, 234); IS4321 and IS5075 (both members of the IS1111 group) target the ends of the transposon Tn21; and ISSba8 (IS1111) inserts into a REP-like sequence located in the end of the IS3 family member, ISSba5.

Therefore, as a general rule, IS110 family elements appear to insert in a sequence-specific and oriented way (236).

\section{IS WITH HUH TRANSPOSASES}

There are two major HUH Tpase families: Y1 and Y2 enzymes (41) according to whether they carry one or two Y residues involved in catalysis. One (Y1) is associated with the IS200/IS605 family. Although these enzymes use the same Y-mediated cleavage mechanism, they appear to carry out the transposition process in quite different ways. The TE that use this type of Tpase do not terminate in IR, which often makes it difficult to determine their ends by bioinformatics analysis unless there are a number of identical copies in a genome.

\section{IS91}

The IS91 family is fairly homogeneous. The canonical IS91 identified three decades ago (54) carries only a single orf, encoding an HUH Y2 Tpase with an Nterminal zinc finger motif (237) (see also reference 41 ). Both Y residues are necessary for transposition (238). The IS does not terminate with extensive IR but includes some potential secondary structure. Several other family members (e.g., ISAzo26, ISCARN110, ISMno23, ISSde12, ISShvi3, ISSod25, and ISWz1) include a second upstream orf related to the phage integrase/ Y-recombinase family. Its role, if any, in transposition remains unclear.

More recently, a second related group, the ISCR (IS with a Common Region) was identified ( $\underline{55}$ ) associated with multiple antibiotic-resistance genes both upstream and downstream of the Tpase gene. They form a distinct class. Although their Tpases are closely related to the IS91 Tpase, they carry a single catalytic Y residue. However, it has yet to be demonstrated that ISCR indeed transpose.

IS91 is thought to transpose using a rolling circle-type mechanism (239) involving an initiation event at one IS end (ori, $3^{\prime}$ to the Tpase), polarized transfer of the IS strand into a target molecule and termination at the second end (ter, $5^{\prime}$ to the Tpase) (238). Sequestration of flanking genes is proposed to occur when the termination mechanism fails and rolling circle transposition extends into neighboring DNA, where it may encounter a second surrogate end (238). This has been estimated to occur at a frequency of about $1 \%$. Indeed, or $i$ is essential for activity whereas removal of ter reduces but does not eliminate transposition.

Insertion of IS91 is oriented with ori adjacent to the $3^{\prime}$ of a specific tetranucleotide target (5'-CTTG or 5'GTTC), which is essential for further transposition (238, 239). In the transposition model, displacement of an IS91 active transposon strand would be driven by leading strand replication of the donor replicon from a 3' 
$\mathrm{OH}$ generated by cleavage at ori. The original model proposed that the cleaved IS end is transferred to the target DNA and the IS is replicated "into" the target replicon. However, it is difficult to explain the occurrence of single- and double-strand IS91 circles on this model and their role remains to be determined. Clearly, since ISCR may play an important role in the assembly and transmission of multiple antibiotic resistance $(\underline{55}$, 240) it is important to address the transposition mechanism of these elements.

IS91 and ISCR Tpases and organization are distantly related to the eukaryotic Helitrons (241) (Thomas and Pritham, this volume).

\section{IS200/IS605}

\section{(i) General}

The IS200/IS605 family (242-244) (He et al., this volume) is divided into three major groups based on the presence or absence of two reading frames, $\operatorname{tnp} A$ (encoding a Y1 Tpase) and $\operatorname{tn} p B$ (whose exact role is unknown) (245). The IS200 group includes tnp $A$ only, the IS1341 (246) group carries only tnpB (and as such its status as an autonomous TE remains questionable), while the third group, IS605, carries both tnpA and $\operatorname{tn} p B$. These can be expressed divergently or sequentially and, in some cases overlap slightly, suggesting translational coupling. TnpB is not required for transposition $(245,247)$ but may have a role in regulation because expression of the protein under control of inducible promoter from ISDra 2 reduces transposition in its original host, Deinococcus radiodurans, and in Escherichia coli (248). TnpB has also been identified in the IS607 family (below) not only in prokaryotes but also in eukaryotes $(\underline{71}, \underline{249})$ where it is sometimes associated with other TE.

\section{(ii) Mechanism}

The IS200/IS605 transposition mechanism is well understood from a combination of genetic, biochemical and structural studies (94, 100, 245, 250-255). Briefly, it occurs using a single-strand "peel-and-paste" mechanism (He et al., this volume) in which a specific single transposon strand (the "top" strand) is excised to form a single-strand transposon circle. This then inserts into a single-strand target. Family members include subterminal secondary structures, which are recognized by TnpA. The cleavage site occurs a short distance $5^{\prime}$ to the left and 3 ' to the right of the structure. These are not directly recognized by TnpA but form a complex set of interactions with the internal sequence permitting their cleavage. Transposition occurs by insertion of the left end $3^{\prime}$ to a specific tetra- or penta-nucleotide, which is also essential for excision and further transposition. Insertion does not generate DR and occurs preferentially into the lagging strand template of replication forks. This results in a clear orientation bias at the genome level reflecting the direction of replication of the target replicon. This can be detected in numerous bacterial genomes. It is also possible that this family targets stalled replication forks (He et al., this volume).

\section{IS WITH SERINE TRANSPOSASES}

The serine recombinase family includes three groups: the resolvase/integrase group (whose activity has been well characterized); the large serine recombinases; and the serine Tpases (256). For the two former groups, the catalytic domain is invariably $\mathrm{N}$-terminal followed by the sequence-specific DNA-binding domain-a simple HTH for the resolvase/invertase group, or a much larger domain of unknown structure in the large serine recombinases (257); (see chapters in the section Conservative Site-Specific Recombination).

\section{IS607}

\section{(i) General}

IS607 was first identified in Helicobacter pylori (258). Family members encode a Tpase related to serine sitespecific recombinase which uses serine as a nucleophile for cleavage of the DNA strand (223). This family is linked to the IS200/IS605 family (above) by the presence of a TnpB analogue. IS607-like elements have been observed in the Mimi virus and other nucleocytoplasmic large DNA viruses (NCLDV) (140). Interestingly it appears to be one of the rare prokaryotic IS identified in eukaryotic genomes $(\underline{71}, \underline{249})$.

\section{(ii) Mechanism}

Little is known about IS607 family transposition although it is thought that circular intermediates are involved (N.D.F. Grindley pers. comm. cited in reference 63). The enzyme presumably catalyzes similar cleavages and strand transfers as its site-specific serine recombinase cousins using a transitory $5^{\prime}$ phosphor-serine covalent intermediate to excise a double-strand circular IS DNA copy. A mechanistic transposition model has been proposed based on Tpase structures from structural genomics studies and detailed knowledge of the general serine recombinase mechanism (256). This imagines a synaptic Tpase tetramer (as for classical serine recombinases) and explains the lack of IS607 target specificity (258), unusual for this type of recombinase. 


\section{(iii) Organization}

In contrast to the serine recombinases, the DNA-binding domain of the serine Tpases is located N-terminal to the catalytic domain $(249,256)$ in a similar way to that of DDE Tpases and may reflect a similar function: folding of the nascent peptide and co-translational binding to the IS ends (see IS3 and IS481 families section above)

\section{ORPHAN IS}

In addition to the major IS groupings, there are also several families for which the Tpase signature is not yet clear, either because there are a number of potential catalytic residues or because there are not a sufficient number of examples to define the highly conserved residues. In the former cases, definition of the important conserved residues will require experimental analysis. In the latter case, the IS are grouped as ISNCY (not classified yet), which includes small numbers of unclassified IS or orphans. Members of this group often emerge as families, or new distant groups of a known family, as more examples are added to the database. For example, both IS1202 and ISDol1 have emerged as groups related to the IS3/IS481 and IS5 families, respectively.

Others include:

IS892: These are 1,600 bp long and represented by two sequences (with additional examples in the public databases). Their Tpases may be produced by frameshifting and include a Pfam MULE-like motif.

ISLbi1: These are 1,400-1,500 bp long and represented by two sequences (with additional examples in the public databases) with a single orf, $30 \mathrm{bp} \mathrm{IR}$ and 5 bp DR.

ISMae2: These are 1,400-2,400 bp long and represented by three sequences (with additional examples in the public databases) with a single orf carrying a potential DDE motif, IR and $9 \mathrm{bp}$ DR. One of these, ISAcif1, includes a passenger gene of unknown function located downstream of the Tpase.

ISPlu15: These are 800-1,000 bp long and represented by two sequences (with additional examples in the public databases). They include a single orf and there are no apparent IR or DR, which makes definition of the IS ends difficult unless they are present in multiple copies.

ISA1214: These are archaeal-specific IS with a length of 1,000-1,200 bp. They are represented by five sequences with IR, with DR of 8 to $12 \mathrm{bp}$ and a small orf upstream of the Tpase expressed in the opposite direction.

ISC1217: These archaeal-specific IS are 1,200 bp long and are represented by four sequences from the Sulfolobales with a single Tpase orf, IR, and DR of 6-8 bp.

ISM1: These archaeal-specific IS are 1,300-1,600 bp long and are represented by six sequences with low conservation and no clear DDE but with IR of about $24 \mathrm{bp}$, DR of 8 or $9 \mathrm{bp}$, and a single orf.

\section{EUKARYOTIC TE AND PROKARYOTIC RELATIVES}

Eukaryotic DNA transposons have been classified into "superfamilies" and, of those that have been analyzed in some detail, many have prokaryotic cousins. These relationships have been highlighted throughout this text. They are Tc1/mariner (IS630), Mutator(MuDR)/ foldback (IS256 and ISLre2), PiggyBac (IS1380), PIF/ Harbinger (IS5), Merlin (IS1595), Banshee (IS3/IS481), and Helitron (IS91). However, several elements with DDE transposases such as hAT, P, CACTA (En/Spm), Transib, Chapaev, Sola, Zator, and Ginger $(\underline{148,200)}$ have yet to find prokaryotic cousins. It seems highly probable that, as the diversity of TE is explored more extensively aided by the massive accumulation of sequence data and the development of software designed to detect TE, more phylogenetic relationships between prokaryotic and eukaryotic TE will become evident.

\section{CONCLUDING REMARKS}

We have divided this review into two major sections. In one, we have attempted to present an overview of our current understanding of prokaryotic IS, their diversity in sequence, in organization and in mechanism, their distribution and impact on their host genome, and their relation to their eukaryotic cousins. We have discussed several IS-related TE that have been identified since the previous edition of Mobile DNA. This includes IS that use single-strand DNA intermediates and their related "domesticated" relations, and ISCR and ICE that use IS-related transposases for excision and integration. Several more specialized chapters in this volume include additional detailed information concerning a number of these topics. One of the major conclusions from this section is that the frontiers between the different types of $\mathrm{TE}$ are becoming less clear as more are identified. 
In the second part, we have provided a detailed description of the expanding variety of IS, which we have divided into families for convenience. We emphasize that there is no "quantitative" measure of the weight of each of the criteria we use to define a family. Our perception of these families continues to evolve and families emerge regularly from the ISNCY "class" as more IS are added. This section is designed to be an aid and a source of information for consultation by interested specialist readers.

It is clear from this survey that there are many important and unanswered questions concerning both mechanistic and regulatory aspects of IS and the way in which they have and continue to spread and colonize their host genomes. An area of particular importance is in understanding the dynamics of TE-driven genome remodeling. A growing view is that the prokaryote genome is an ecological niche populated by a diverse collection of TE, in particular IS, including both endogenous elements and those acquired serendipitously by horizontal transfer. These form an integral part of a genomic landscape which is continuously modified by their activity. Understanding the evolutionary relationship between genomes and TE in this ecological niche and of the dynamics of TE-mediated genome remodeling is one of the fundamental challenges in genomics.

\section{REFERENCES}

1. Fiandt M, Szybalski W, Malamy MH. 1972. Polar mutations in lac, gal and phage lambda consist of a few IS- DNA sequences inserted with either orientation. Mol Gen Genet 119:223-231.

2. Hirsch HJ, Saedler H, Starlinger P. 1972. Insertion mutations in the control region of the galactose operon of E. coli. II. Physical characterization of the mutations. Mol Gen Genet 115:266-276.

3. Hirsch HJ, Starlinger P, Brachet P. 1972. Two kinds of insertions in bacterial genes. Mol Gen Genet 119:191-206.

4. Saedler H, Heiss B. 1973. Multiple copies of the insertion-DNA sequences IS1 and IS2 in the chromosome of E. coli K-12. Mol Gen Genet 122:267-277.

5. Reif HJ, Saedler H. 1974. IS1 is Involved in Deletion Formation in the gal Region of E.coli K12. Mol Gen Genet 137:17-28.

6. Saedler H, Reif HJ, Hu S, Davidson N. 1974. IS2, a genetic element for turn-off and turn-on of gene activity in E. coli. Mol Gen Genet 132: 265-289.

7. Hu S, Ohtsubo E, Davidson N. 1975. Electron microscopic heteroduplex studies of sequence relations among plasmids of Escherichia coli: structure of F13 and related F-primes. J Bacteriol 122:749-763.

8. Barth PT, Datta N, Hedges RW, Grinter NJ. 1976. Transposition of a deoxyribonucleic acid sequence encoding trimethoprim and streptomycin resistances from R483 to other replicons. J Bacteriol 125:800-810.

9. Hedges RW, Jacob AE. 1974. Transposition of ampicillin resistance from RP4 to other replicons. Mol Gen Genet 132:31-40.

10. Heffron F, Sublett R, Hedges RW, Jacob A, Falkow S. 1975. Origin of the TEM-beta-lactamase gene found on plasmids. J Bacteriol 122: 250-256.

11. Arber W, lida S, Jutte H, Caspers P, Meyer J, Hanni C. 1979. Rearrangements of genetic material in Escherichia coli as observed on the bacteriophage P1 plasmid. Cold Spring Harb Symp Quant Biol 43(Pt 2):1197-1208.

12. So M, Heffron F, McCarthy BJ. 1979. The E. coli gene encoding heat stable toxin is a bacterial transposon flanked by inverted repeats of IS1. Nature 277:453-456.

13. Nevers P, Saedler H. 1977. Transposable genetic elements as agents of gene instability and chromosomal rearrangements. Nature 268:109115 .

14. McClintock B. 1956. Controlling elements and the gene. Cold Spring Harb Symp Quant Biol 21:197-216.

15. Nyman K, Nakamura K, Ohtsubo H, Ohtsubo E. 1981. Distribution of the insertion sequence IS1 in gram-negative bacteria. Nature 289:609612.

16. Ohtsubo H, Nyman K, Doroszkiewicz W, Ohtsubo E. 1981. Multiple copies of iso-insertion sequences of IS1 in Shigella dysenteriae chromosome. Nature 292:640-643.

17. Aziz RK, Breitbart M, Edwards RA. 2010. Transposases are the most abundant, most ubiquitous genes in nature. Nucleic Acids Res 38:42074217.

18. Berg DE, Howe MM. 1989. Mobile DNA. American Society for Microbiology, Washington DC.

19. Craig NL, Craigie R, Gellert M, Lambowitz A. 2002. Mobile DNA II. American Society of Microbiology, Washington DC.

20. Siguier P, Gourbeyre E, Chandler M. 2014. Bacterial insertion sequences: their genomic impact and diversity. FEMS Microbiol Rev 38:865-891.

21. Sharma V, Firth AE, Antonov I, Fayet O, Atkins JF, Borodovsky M, Baranov PV. 2011. A pilot study of bacterial genes with disrupted ORFs reveals a surprising profusion of protein sequence recoding mediated by ribosomal frameshifting and transcriptional realignment. Mol Biol Evol 28:3195-3211.

22. Siguier P, Perochon J, Lestrade L, Mahillon J, Chandler M. 2006. ISfinder: the reference centre for bacterial insertion sequences. Nucleic Acids Res 34:D32-D36.

23. Campbell A, Berg DE, Botstein D, Lederberg EM, Novick RP, Starlinger P, Szybalski W. 1979. Nomenclature of transposable elements in prokaryotes. Gene 5:197-206.

24. Mahillon J, Chandler M. 2000. Insertion sequence nomenclature. ASM News 66:324.

25. Galas DJ, Chandler M. 1989. Bacterial insertion sequences, p 109-162. In Berg D, Howe M (ed), Mobile DNA. American Society for Microbiology, Washington DC.

26. Chandler M, Mahillon J. 2002. Insertion sequences revisited, p 305366. In Craig NL, Craigie R, Gellert M, Lambowitz A (ed), Mobile DNA, vol II. ASM Press, Washington DC.

27. Mizuuchi K, Baker TA. 2002. Chemical mechanisms for mobilizing DNA, p 12-23. In Craig NL, Craigie R, Gellert M, Lambowitz A (ed), Mobile DNA, vol II. ASM press, Washington DC.

28. Fayet O, Ramond P, Polard P, Prere MF, Chandler M. 1990. Functional similarities between retroviruses and the IS3 family of bacterial insertion sequences? Mol Microbiol 4:1771-1777.

29. Kulkosky J, Jones KS, Katz RA, Mack JP, Skalka AM. 1992. Residues critical for retroviral integrative recombination in a region that is highly conserved among retroviral/retrotransposon integrases and bacterial insertion sequence transposases. Mol Cell Biol 12:23312338 .

30. Khan E, Mack JP, Katz RA, Kulkosky J, Skalka AM. 1991. Retroviral integrase domains: DNA binding and the recognition of LTR sequences [published erratum appears in Nucleic Acids Res 1991 Mar 25;19(6):1358]. Nucleic Acids Res 19:851-860.

31. Hickman AB, Chandler M, Dyda F. 2010. Integrating prokaryotes and eukaryotes: DNA transposases in light of structure. Crit Rev Biochem Mol Biol 45:50-69. 
32. Davies DR, Braam LM, Reznikoff WS, Rayment I. 1999. The threedimensional structure of a $\operatorname{Tn} 5$ transposase-related protein determined to 2.9-A resolution. J Biol Chem 274:11904-11913.

33. Hickman AB, Perez ZN, Zhou L, Musingarimi P, Ghirlando R, Hinshaw JE, Craig NL, Dyda F. 2005. Molecular architecture of a eukaryotic DNA transposase. Nat Struct Mol Biol 12:715-721.

34. Curcio MJ, Derbyshire KM. 2003. The outs and ins of transposition: from Mu to Kangaroo. Nat Rev Mol Cell Biol 4:865-877.

35. Turlan C, Chandler M. 2000. Playing second fiddle: second-strand processing and liberation of transposable elements from donor DNA. Trends Microbiol 8:268-274.

36. Feng X, Colloms SD. 2007. In vitro transposition of ISY100, a bacterial insertion sequence belonging to the Tc1/mariner family. Mol Microbiol 65:1432-1443.

37. Plasterk RH. 1996. The Tc1/mariner transposon family. Curr Top Microbiol Immunol 204:125-143.

38. Zhou L, Mitra R, Atkinson PW, Burgess Hickman A, Dyda F, Craig NL. 2004. Transposition of hAT elements links transposable elements and V(D)J recombination. Nature 432:995-1001.

39. Choi S, Ohta S, Ohtsubo E. 2003. A novel IS element, IS621, of the IS110/IS492 family transposes to a specific site in repetitive extragenic palindromic sequences in Escherichia coli. J Bacteriol 185:48914900.

40. Buchner JM, Robertson AE, Poynter DJ, Denniston SS, Karls AC. 2005. Piv site-specific invertase requires a DEDD motif analogous to the catalytic center of the RuvC Holliday junction resolvases. J Bacteriol 187:3431-3437.

41. Chandler M, de la Cruz F, Dyda F, Hickman AB, Moncalian G, Ton-Hoang B. 2013. Breaking and joining single-stranded DNA: the HUH endonuclease superfamily. Nat Rev Microbiol 11:525-538.

42. Taylor KL, Churchward G. 1997. Specific DNA cleavage mediated by the integrase of conjugative transposon Tn916. J Bacteriol 179:11171125 .

43. Siguier P, Gagnevin L, Chandler M. 2009. The new IS1595 family, its relation to IS1 and the frontier between insertion sequences and transposons. Res Microbiol 160:232-241.

44. Liebert CA, Hall RM, Summers AO. 1999. Transposon Tn21, Flagship of the Floating Genome. Microbiol Mol Biol Rev 63:507-522.

45. Mazel D. 2006. Integrons: agents of bacterial evolution. Nat Rev Microbiol 4:608-620.

46. Nakatsu C, Ng J, Singh R, Straus N, Wyndham C. 1991. Chlorobenzoate catabolic transposon Tn5271 is a composite class I element with flanking class II insertion sequences. Proc Natl Acad Sci USA 88:83128316.

47. Burrus V, Waldor MK. 2004. Shaping bacterial genomes with integrative and conjugative elements. Res Microbiol 155:376-386.

48. Adams V, Lyras D, Farrow KA, Rood JI. 2002. The clostridial mobilisable transposons. Cell Mol Life Sci 59:2033-2043.

49. Pavlovic G, Burrus V, Gintz B, Decaris B, Guedon G. 2004. Evolution of genomic islands by deletion and tandem accretion by site-specific recombination: ICESt1-related elements from Streptococcus thermophilus. Microbiology 150:759-774.

50. Brochet M, Da Cunha V, Couve E, Rusniok C, Trieu-Cuot P, Glaser P. 2009. Atypical association of DDE transposition with conjugation specifies a new family of mobile elements. Mol Microbiol 71:948-959.

51. Guerillot R, Da Cunha V, Sauvage E, Bouchier C, Glaser P. 2013. Modular evolution of TnGBSs, a new family of integrative and conjugative elements associating insertion sequence transposition, plasmid replication, and conjugation for their spreading. J Bacteriol 195:1979-1990.

52. Guerillot R, Siguier P, Gourbeyre E, Chandler M, Glaser P. 2014. The diversity of prokaryotic DDE transposases of the mutator superfamily, insertion specificity, and association with conjugation machineries. Genome Biol Evol 6:260-272.
53. Smyth DS, Robinson DA. 2009. Integrative and sequence characteristics of a novel genetic element, ICE6013, in Staphylococcus aureus. J Bacteriol 191:5964-5975.

54. Diaz-Aroca E, de la Cruz F, Zabala JC, Ortiz JM. 1984. Characterization of the new insertion sequence IS91 from an alpha-hemolysin plasmid of Escherichia coli. Mol Gen Genet 193:493-499.

55. Toleman MA, Bennett PM, Walsh TR. 2006. ISCR Elements: Novel Gene-Capturing Systems of the 21st Century? Microbiol Mol Biol Rev 70:296-316.

56. Toleman MA, Walsh TR. 2010. ISCR elements are key players in IncA/C plasmid evolution. Antimicrob Agents Chemother 54:3534; author reply 3534 .

57. Feschotte C, Zhang X, Wessler S. 2002. Miniature inverted repeat transposable elements and their relationship to established DNA transposons, p 1147-1158. In Craig NL, Craigie R, Gellert M, Lambowitz A (ed), Mobile DNA, vol II. ASM Press, Washington DC.

58. Dyall-Smith ML, Pfeiffer F, Klee K, Palm P, Gross K, Schuster SC, Rampp M, Oesterhelt D. 2011. Haloquadratum walsbyi: limited diversity in a global pond. PLOS ONE 6:e20968.

59. Correia FF, Inouye S, Inouye M. 1988. A family of small repeated elements with some transposon-like properties in the genome of Neisseria gonorrhoeae. J Biol Chem 263:12194-12198.

60. Buisine N, Tang CM, Chalmers R. 2002. Transposon-like Correia elements: structure, distribution and genetic exchange between pathogenic Neisseria sp. FEBS Lett 522:52-58.

61. Oggioni MR, Claverys JP. 1999. Repeated extragenic sequences in prokaryotic genomes: a proposal for the origin and dynamics of the RUP element in Streptococcus pneumoniae. Microbiology 145(Pt 10):26472653.

62. Brugger K, Redder P, She Q, Confalonieri F, Zivanovic Y, Garrett RA. 2002. Mobile elements in archaeal genomes. FEMS Microbiol Lett 206:131-141.

63. Filee J, Siguier P, Chandler M. 2007. Insertion sequence diversity in archaea. Microbiol Mol Biol Rev 71:121-157.

64. Chen Y, Braathen P, Léonard C, Mahillon J. 1999. MIC231, a naturally occurring mobile insertion cassette from Bacillus cereus. Mol Microbiol 32:657-668.

65. De Palmenaer D, Vermeiren C, Mahillon J. 2004. IS231-MIC231 elements from Bacillus cereus sensu lato are modular. Mol Microbiol 53:457-467.

66. Demerec M, Adelberg EA, Clark AJ, Hartman PE. 1966. A proposal for a uniform nomenclature in bacterial genetics. Genetics 54:61-76.

67. Nagy Z, Chandler M. 2004. Regulation of transposition in bacteria. Res Microbiol 155:387-398.

68. Dumesic PA, Madhani HD. 2014. Recognizing the enemy within: licensing RNA-guided genome defense. Trends Biochem Sci 39:25-34.

69. Fedoroff NV. 2012. Transposable elements, epigenetics, and genome evolution. Science 338:758-767.

70. Bikard D, Marraffini LA. 2013. Control of Gene Expression by CRISPR-Cas systems. F1000Prime Rep 5:47.

71. Bao W, Jurka J. 2013. Homologues of bacterial TnpB_IS605 are widespread in diverse eukaryotic transposable elements. Mob DNA 4:12.

72. Parkhill J, Sebaihia M, Preston A, Murphy LD, Thomson N, Harris DE, Holden MT, Churcher CM, Bentley SD, Mungall KL, CerdenoTarraga AM, Temple L, James K, Harris B, Quail MA, Achtman M, Atkin R, Baker S, Basham D, Bason N, Cherevach I, Chillingworth T, Collins M, Cronin A, Davis P, Doggett J, Feltwell T, Goble A, Hamlin N, Hauser H, Holroyd S, Jagels K, Leather S, Moule S, Norberczak H, O’Neil S, Ormond D, Price C, Rabbinowitsch E, Rutter S, Sanders M, Saunders D, Seeger K, Sharp S, Simmonds M, Skelton J, Squares R, Squares S, Stevens $\mathrm{K}$, Unwin L, et al. 2003. Comparative analysis of the genome sequences of Bordetella pertussis, Bordetella parapertussis and Bordetella bronchiseptica. Nat Genet 35:32-40. 
73. Preston A, Parkhill J, Maskell DJ. 2004. The Bordetellae: lessons from genomics. Nat Rev Microbiol 2:379-390.

74. Touchon M, Rocha EP. 2007. Causes of insertion sequences abundance in prokaryotic genomes. Mol Biol Evol 24:969-981.

75. Gil R, Belda E, Gosalbes MJ, Delaye L, Vallier A, Vincent-Monegat C, Heddi A, Silva FJ, Moya A, Latorre A. 2008. Massive presence of insertion sequences in the genome of SOPE, the primary endosymbiont of the rice weevil Sitophilus oryzae. Int Microbiol 11:41-48.

76. Plague GR, Dunbar HE, Tran PL, Moran NA. 2008. Extensive proliferation of transposable elements in heritable bacterial symbionts. J Bacteriol 190:777-779.

77. Moran NA, Plague GR. 2004. Genomic changes following host restriction in bacteria. Curr Opin Genet Dev 14:627-633.

78. Andersson JO, Andersson SG. 1999. Insights into the evolutionary process of genome degradation. Curr Opin Genet Dev 9:664-671.

79. Lawrence JG, Hendrix RW, Casjens S. 2001. Where are the pseudogenes in bacterial genomes? Trends Microbiol 9:535-540.

80. Mira A, Ochman H, Moran NA. 2001. Deletional bias and the evolution of bacterial genomes. Trends Genet 17:589-596.

81. Cerveau N, Leclercq S, Leroy E, Bouchon D, Cordaux R. 2011. Shortand long-term evolutionary dynamics of bacterial insertion sequences: insights from Wolbachia endosymbionts. Genome Biol Evol 3:11751186.

82. Glansdorff N, Charlier D, Zafarullah M. 1981. Activation of gene expression by IS2 and IS3. Cold Spring Harb Symp Quant Biol $45(\mathrm{Pt}$ 1):153-156.

83. Soki J, Eitel Z, Urban E, Nagy E. 2013. Molecular analysis of the carbapenem and metronidazole resistance mechanisms of Bacteroides strains reported in a Europe-wide antibiotic resistance survey. Int $J$ Antimicrob Agents 41:122-125.

84. Aubert D, Naas T, Heritier C, Poirel L, Nordmann P. 2006. Functional characterization of IS1999, an IS4 family element involved in mobilization and expression of beta-lactam resistance genes. J Bacteriol 188:6506-6514.

85. Kieny M-P. 2012. The evolving threat of antimicrobial resistance: options for action. World Health Organization, Geneva.

86. McKenna M. 2013. The Last Resort. Nature 499:394-396.

87. Mole B. 2013. Farming up trouble. Nature 499:398-400.

88. Simons RW, Hoopes BC, McClure WR, Kleckner N. 1983. Three promoters near the termini of IS10: pIN, pOUT, and pIII. Cell 34:673682.

89. Ton-Hoang B, Betermier M, Polard P, Chandler M. 1997. Assembly of a strong promoter following IS911 circularization and the role of circles in transposition. EMBO J 16:3357-3371.

90. Perkins-Balding D, Duval-Valentin G, Glasgow AC. 1999. Excision of IS492 requires flanking target sequences and results in circle formation in Pseudoalteromonas atlantica. J Bacteriol 181:4937-4948.

91. Duval-Valentin G, Normand C, Khemici V, Marty B, Chandler M. 2001. Transient promoter formation: a new feedback mechanism for regulation of IS911 transposition. EMBO J 20:5802-5811.

92. Prentki P, Teter B, Chandler M, Galas DJ. 1986. Functional promoters created by the insertion of transposable element IS1. J Mol Biol 191:383-393.

93. Depardieu F, Podglajen I, Leclercq R, Collatz E, Courvalin P. 2007. Modes and modulations of antibiotic resistance gene expression. Clin Microbiol Rev 20:79-114.

94. Guynet C, Achard A, Hoang BT, Barabas O, Hickman AB, Dyda F, Chandler M. 2009. Resetting the site: redirecting integration of an insertion sequence in a predictable way. Mol Cell 34:612-619.

95. Mendiola MV, de la Cruz F. 1989. Specificity of insertion of IS91, an insertion sequence present in alpha-haemolysin plasmids of Escherichia coli. Mol Microbiol 3:979-984.
96. Galas DJ, Calos MP, Miller JH. 1980. Sequence analysis of Tn9 insertions in the lacZ gene. J Mol Biol 144:19-41.

97. Meyer J, lida S, Arber W. 1980. Does the insertion element IS1 transpose preferentially into A+T- rich DNA segments? Mol Gen Genet 178:471-473.

98. Sengstag C, Iida S, Hiestand-Nauer R, Arber W. 1986. Terminal inverted repeats of prokaryotic transposable element IS186 which can generate duplications of variable length at an identical target sequence. Gene 49:153-156.

99. Peters JE, Craig NL. 2001. Tn7: smarter than we thought. Nat Rev Mol Cell Biol 2:806-814.

100. Ton-Hoang B, Pasternak C, Siguier P, Guynet C, Hickman AB, Dyda F, Sommer S, Chandler M. 2010. Single-stranded DNA transposition is coupled to host replication. Cell 142:398-408.

101. Hu WY, Derbyshire KM. 1998. Target choice and orientation preference of the insertion sequence IS903. J Bacteriol 180:3039-3048.

102. Spradling AC, Bellen HJ, Hoskins RA. 2011. Drosophila P elements preferentially transpose to replication origins. Proc Natl Acad Sci U S A 108:15948-15953.

103. Peters JE, Craig NL. 2000. Tn7 transposes proximal to DNA doublestrand breaks and into regions where chromosomal DNA replication terminates. Mol Cell 6:573-582.

104. Shi Q, Huguet-Tapia JC, Peters JE. 2009. Tn917 Targets the Region Where DNA Replication Terminates in Bacillus subtilis, Highlighting a Difference in Chromosome Processing in the Firmicutes. J Bacteriol 191:7623-7627.

105. Garsin DA, Urbach J, Huguet-Tapia JC, Peters JE, Ausubel FM. 2004. Construction of an Enterococcus faecalis Tn917-mediated-genedisruption library offers insight into Tn917 insertion patterns. J Bacteriol 186:7280-7289.

106. Slater JD, Allen AG, May JP, Bolitho S, Lindsay H, Maskell DJ. 2003. Mutagenesis of Streptococcus equi and Streptococcus suis by transposon Tn917. Vet Microbiol 93:197-206.

107. Swingle B, O'Carroll M, Haniford D, Derbyshire KM. 2004. The effect of host-encoded nucleoid proteins on transposition: H-NS influences targeting of both IS903 and Tn10. Mol Microbiol 52:10551067.

108. Clement J-M, Wilde C, Bachellier S, Lambert P, Hofnung M. 1999. IS1397 Is Active for Transposition into the Chromosome of Escherichia coli K-12 and Inserts Specifically into Palindromic Units of Bacterial Interspersed Mosaic Elements. J Bacteriol 181:6929-6936.

109. Tobes R, Pareja E. 2006. Bacterial repetitive extragenic palindromic sequences are DNA targets for Insertion Sequence elements. BMC Genomics 7:62.

110. Wilde C, Escartin F, Kokeguchi S, Latour-Lambert P, Lectard A, Clement JM. 2003. Transposases are responsible for the target specificity of IS1397 and ISKpn1 for two different types of palindromic units (PUs). Nucleic Acids Res 31:4345-4353.

111. Tetu SG, Holmes AJ. 2008. A Family of Insertion Sequences That Impacts Integrons by Specific Targeting of Gene Cassette Recombination Sites, the IS1111-attC Group. J Bacteriol 190:4959-4970.

112. Post V, Hall RM. 2009. Insertion sequences in the IS1111 family that target the attC recombination sites of integron-associated gene cassettes. FEMS Microbiol Lett 290:182-187.

113. Hallet B, Rezsohazy R, Delcour J. 1991. IS231A from Bacillus thuringiensis is functional in Escherichia coli: transposition and insertion specificity. J Bacteriol 173:4526-4529.

114. Partridge SR, Hall RM. 2003. The IS1111 family members IS4321 and IS5075 have subterminal inverted repeats and target the terminal inverted repeats of Tn21 family transposons. J Bacteriol 185:6371-6384. 115. Loot C, Turlan C, Chandler M. 2004. Host processing of branched DNA intermediates is involved in targeted transposition of IS911. Mol Microbiol 51:385-393. 
116. Reimmann C, Haas D. 1987. Mode of replicon fusion mediated by the duplicated insertion sequence IS21 in Escherichia coli. Genetics 115:619-625.

117. Olasz F, Farkas T, Kiss J, Arini A, Arber W. 1997. Terminal inverted repeats of insertion sequence IS30 serve as targets for transposition. J Bacteriol 179:7551-7558.

118. Prere MF, Chandler M, Fayet O. 1990. Transposition in Shigella dysenteriae: isolation and analysis of IS911, a new member of the IS3 group of insertion sequences. J Bacteriol 172:4090-4099.

119. Parks AR, Li Z, Shi Q, Owens RM, Jin MM, Peters JE. 2009. Transposition into replicating DNA occurs through interaction with the processivity factor. Cell 138:685-695.

120. Gomez MJ, Diaz-Maldonado H, Gonzalez-Tortuero E, Lopez de Saro FJ. 2014. Chromosomal replication dynamics and interaction with the beta sliding clamp determine orientation of bacterial transposable elements. Genome Biol Evol 6:727-740.

121. Qi X, Daily K, Nguyen K, Wang H, Mayhew D, Rigor P, Forouzan S, Johnston M, Mitra RD, Baldi P, Sandmeyer S. 2012. Retrotransposon profiling of RNA polymerase III initiation sites. Genome Res 22:681-692. 122. Shapiro JA. 1979. Molecular model for the transposition and replication of bacteriophage $\mathrm{Mu}$ and other transposable elements. Proc Natl Acad Sci USA 76:1933-1937.

123. Ross DG, Swan J, Kleckner N. 1979. Nearly precise excision: a new type of DNA alteration associated with the translocatable element $\operatorname{Tn} 10$. Cell 16:733-738.

124. Ross DG, Swan J, Kleckner N. 1979. Physical structures of Tn10promoted deletions and inversions: role of $1400 \mathrm{bp}$ inverted repetitions. Cell 16:721-731.

125. Ohtsubo E, Zenilman M, Ohtsubo H. 1980. Plasmids containing insertion elements are potential transposons. Proc Natl Acad Sci U S A 77:750-754.

126. Polard P, Seroude L, Fayet O, Prere MF, Chandler M. 1994. Oneended insertion of IS911. J Bacteriol 176:1192-1196.

127. Mahillon J, Chandler M. 1998. Insertion sequences. Microbiol Mol Biol Rev 62:725-774.

128. Robinson DG, Lee MC, Marx CJ. 2012. OASIS: an automated program for global investigation of bacterial and archaeal insertion sequences. Nucleic Acids Res 40:e174.

129. Wagner A, Lewis C, Bichsel M. 2007. A survey of bacterial insertion sequences using IScan. Nucleic Acids Res 35:5284-5293.

130. MacHattie LA, Jackowski JB. 1977. Physical Structure and Deletion Effects of the Chloramphenicol Resistance Element Tn9 in Phage Lambda, p 219-228. In Bukhari AI, Shapiro JA, Adhya SL (ed), DNA Insertion Elements, Plasmids, and Episomes. Cold Spring Harbour Laboratory, New York.

131. Chandler M, Silver L, Lane D, Caro L. 1979. Properties of an autonomous r-determinant from R100.1. Cold Spring Harb Symp Quant Biol 43(Pt 2):1223-1231.

132. Peterson BC, Rownd RH. 1985. Recombination sites in plasmid drug resistance gene amplification. J Bacteriol 164:1359-1361.

133. Blinkowa AL, Walker JR. 1990. Programmed ribosomal frameshifting generates the Escherichia coli DNA polymerase III gamma subunit from within the tau subunit reading frame. Nucleic Acids Res 18:1725-1729.

134. Matsutani S. 1994. Genetic evidence for IS1 transposition regulated by InsA and the delta InsA-B'-InsB species, which is generated by translation from two alternative internal initiation sites and frameshifting. J Mol Biol 240:52-65.

135. Ton-Hoang B, Turlan C, Chandler M. 2004. Functional domains of the IS1 transposase: analysis in vivo and in vitro. Mol Microbiol 53:15291543.

136. Turlan C, Chandler M. 1995. IS1-mediated intramolecular rearrangements: formation of excised transposon circles and replicative deletions. EMBO J 14:5410-5421.
137. Ohta S, Tsuchida K, Choi S, Sekine Y, Shiga Y, Ohtsubo E. 2002. Presence of a characteristic D-D-E motif in IS1 transposase. J Bacteriol 184:6146-6154.

138. Ohta S, Yoshimura E, Ohtsubo E. 2004. Involvement of two domains with helix-turn-helix and zinc finger motifs in the binding of IS1 transposase to terminal inverted repeats. Mol Microbiol 53:193202.

139. Parkhill J, Achtman M, James KD, Bentley SD, Churcher C, Klee SR, Morelli G, Basham D, Brown D, Chillingworth T, Davies RM, Davis P, Devlin K, Feltwell T, Hamlin N, Holroyd S, Jagels K, Leather S, Moule S, Mungall K, Quail MA, Rajandream MA, Rutherford KM, Simmonds M, Skelton J, Whitehead S, Spratt BG, Barrell BG. 2000. Complete DNA sequence of a serogroup A strain of Neisseria meningitidis Z2491. Nature 404:502-506.

140. Filée J, Siguier P, Chandler M. 2007. I am what I eat and I eat what I am: acquisition of bacterial genes by giant viruses. Trends Genet 23:1015 .

141. Achard A, Leclercq R. 2007. Characterization of a small mobilizable transposon, MTnSag1, in Streptococcus agalactiae. J Bacteriol 189:43284331.

142. Feschotte C. 2004. Merlin, a new superfamily of DNA transposons identified in diverse animal genomes and related to bacterial IS1016 insertion sequences. Mol Biol Evol 21:1769-1780.

143. Rousseau P, Normand C, Loot C, Turlan C, Alazard R, DuvalValentin G, Chandler M. 2002. Transposition of IS911, p 366-383. In Craig NL, Craigie R, Gellert M, Lambowitz A (ed), Mobile DNA II. American Society of Microbiology, Washington DC.

144. Bhugra B, Dybvig K. 1993. Identification and characterization of IS1138, a transposable element from Mycoplasma pulmonis that belongs to the IS3 family. Mol Microbiol 7:577-584.

145. Smith KS, Ingram-Smith C. 2007. Methanosaeta, the forgotten methanogen? Trends Microbiol 15:150-155.

146. Petrova M, Shcherbatova N, Gorlenko Z, Mindlin S. 2013. A new subgroup of the IS3 family and properties of its representative member ISPy1. Microbiology 159:1900-1910.

147. Duval-Valentin G, Chandler M. 2011. Cotranslational control of DNA transposition: a window of opportunity. Mol Cell 44:989-996.

148. Feschotte C, Pritham EJ. 2007. DNA Transposons and the Evolution of Eukaryotic Genomes. Annu Rev Genet 41:331-368.

149. Morona JK, Guidolin A, Morona R, Hansman D, Paton JC. 1994. Isolation, characterization, and nucleotide sequence of IS1202, an insertion sequence of Streptococcus pneumoniae. J Bacteriol 176:44374443.

150. De Palmenaer D, Siguier P, Mahillon J. 2008. IS4 family goes genomic. BMC Evol Biol 8:18.

151. Rezsohazy R, Hallet B, Delcour J, Mahillon J. 1993. The IS4 family of insertion sequences: evidence for a conserved transposase motif. Mol Microbiol 9:1283-1295.

152. Davies DR, Goryshin IY, Reznikoff WS, Rayment I. 2000. Threedimensional structure of the Tn5 synaptic complex transposition intermediate. Science 289:77-85.

153. Mazel D, Bernard C, Schwarz R, Castets AM, Houmard J, Tandeau de Marsac N. 1991. Characterization of two insertion sequences, IS701 and IS702, from the cyanobacterium Calothrix species PCC 7601. Mol Microbiol 5:2165-2170.

154. Vilei EM, Nicolet J, Frey J. 1999. IS1634, a Novel Insertion Element Creating Long, Variable-Length Direct Repeats Which Is Specific for Mycoplasma mycoides subsp. mycoides Small-Colony Type. J Bacteriol 181:1319-1323.

155. Klenchin VA, Czyz A, Goryshin IY, Gradman R, Lovell S, Rayment I, Reznikoff WS. 2008. Phosphate coordination and movement of DNA in the Tn5 synaptic complex: role of the (R)YREK motif 10.1093/nar/ gkn577. Nucl Acids Res 36:5855-5862. 
156. Rieck B, Tourigny DS, Crosatti M, Schmid R, Kochar M, Harrison EM, Ou HY, Turton JF, Rajakumar K. 2012. Acinetobacter insertion sequence ISAba11 belongs to a novel family that encodes transposases with a signature HHEK motif. Appl Environ Microbiol 78:471-480.

157. Zhang X, Jiang N, Feschotte C, Wessler SR. 2004. PIF- and Pong-like transposable elements: distribution, evolution and relationship with Tourist-like miniature inverted-repeat transposable elements. Genetics 166:971-986.

158. Berg DE, Davies J, Allet B, Rochaix JD. 1975. Transposition of R factor genes to bacteriophage lambda. Proc Natl Acad Sci USA 72:3628-3632.

159. Miriagou V, Carattoli A, Tzelepi E, Villa L, Tzouvelekis LS. 2005. IS26-Associated In4-Type Integrons Forming Multiresistance Loci in Enterobacterial Plasmids. Antimicrob Agents Chemother 49:3541-3543.

160. Partridge SR, Zong Z, Iredell JR. 2011. Recombination in IS26 and $\mathrm{Tn} 2$ in the Evolution of Multiresistance Regions Carrying blaCTX-M-15 on Conjugative IncF Plasmids from Escherichia coli. Antimicrob Agents Chemother 55:4971-4978.

161. Zhu Y-G, Johnson TA, Su J-Q, Qiao M, Guo G-X, Stedtfeld RD, Hashsham SA, Tiedje JM. 2013. Diverse and abundant antibiotic resistance genes in Chinese swine farms. Proc Natl Acad Sci USA 110:3435-3440.

162. Kato K, Ohtsuki K, Mitsuda H, Yomo T, Negoro S, Urabe I. 1994. Insertion sequence IS6100 on plasmid pOAD2, which degrades nylon oligomers. J Bacteriol 176:1197-1200.

163. Hall RM, Brown HJ, Brookes DE, Stokes HW. 1994. Integrons found in different locations have identical $5^{\prime}$ ends but variable $3^{\prime}$ ends. J Bacteriol 176:6286-6294.

164. Sundin GW, Bender CL. 1995. Expression of the strA-strB streptomycin resistance genes in Pseudomonas syringae and Xanthomonas campestris and characterization of IS6100 in X. campestris. Appl Environ Microbiol 61:2891-2897.

165. Simpson AE, Skurray RA, Firth N. 2000. An IS257-derived hybrid promoter directs transcription of a tet $\mathrm{A}(\mathrm{K})$ tetracycline resistance gene in the Staphylococcus aureus chromosomal mec region. J Bacteriol 182: 3345-3352.

166. Bertini A, Poirel L, Bernabeu S, Fortini D, Villa L, Nordmann P, Carattoli A. 2007. Multicopy blaOXA-58 gene as a source of high-level resistance to carbapenems in Acinetobacter baumannii. Antimicrob Agents Chemother 51:2324-2328.

167. Zienkiewicz M, Kern-Zdanowicz I, Carattoli A, Gniadkowski M, Ceglowski P. 2013. Tandem multiplication of the IS26-flanked amplicon with the bla(SHV-5) gene within plasmid p1658/97. FEMS Microbiol Lett 341:27-36.

168. Loli A, Tzouvelekis LS, Tzelepi E, Carattoli A, Vatopoulos AC, Tassios PT, Miriagou V. 2006. Sources of diversity of carbapenem resistance levels in Klebsiella pneumoniae carrying blaVIM-1. J Antimicrob Chemother 58:669-672.

169. Doublet B, Praud K, Weill FX, Cloeckaert A. 2009. Association of IS26-composite transposons and complex In4-type integrons generates novel multidrug resistance loci in Salmonella genomic island 1. J Antimicrob Chemother 63:282-289.

170. Nigro SJ, Farrugia DN, Paulsen IT, Hall RM. 2013. A novel family of genomic resistance islands, AbGRI2, contributing to aminoglycoside resistance in Acinetobacter baumannii isolates belonging to global clone 2 . J Antimicrob Chemother 68:554-557.

171. Cullik A, Pfeifer Y, Prager R, von Baum H, Witte W. 2010. A novel IS26 structure surrounds blaCTX-M genes in different plasmids from German clinical Escherichia coli isolates. J Med Microbiol 59:580-587.

172. Trieu-Cuot P, Courvalin P. 1985. Transposition behavior of IS15 and its progenitor IS15-delta: are cointegrates exclusive end products? Plasmid 14:80-89.

173. Harmer CJ, Moran RA, Hall RM. 2014. Movement of IS26associated antibiotic resistance genes occurs via a translocatable unit that includes a single IS26 and preferentially inserts adjacent to another IS26. MBio 5:e01801-01814.
174. Riess G, Holloway BW, Puhler A. 1980. R68.45, a plasmid with chromosome mobilizing ability (Cma) carries a tandem duplication. Genet Res 36:99-109.

175. Willetts NS, Crowther C, Holloway BW. 1981. The insertion sequence IS21 of R68.45 and the molecular basis for mobilization of the bacterial chromosome. Plasmid 6:30-52.

176. Watson JM, Holloway BW. 1978. Chromosome mapping in Pseudomonas aeruginosa PAT. J Bacteriol 133:1113-1125.

177. Berger B, Haas D. 2001. Transposase and cointegrase: specialized transposition proteins of the bacterial insertion sequence IS21 and related elements. Cell Mol Life Sci 58:403-419.

178. Ammendola S, Politi L, Scandurra R. 1998. Cloning and sequencing of ISC1041 from the archaeon Sulfolobus solfataricus MT-4, a new member of the IS30 family of insertion elements [In Process Citation]. FEBS Lett 428:217-223.

179. Dalrymple B. 1987. Novel rearrangements of IS30 carrying plasmids leading to the reactivation of gene expression. Mol Gen Genet 207:413420.

180. Rasmussen JL, Odelson DA, Macrina FL. 1987. Complete nucleotide sequence of insertion element IS4351 from Bacteroides fragilis. J Bacteriol 169:3573-3580.

181. Rudant E, Courvalin P, Lambert T. 1998. Characterization of IS18, an Element Capable of Activating the Silent aac $\left(6^{\prime}\right)-\mathrm{Ij}$ Gene of Acinetobacter sp. 13 Strain BM2716 by Transposition. Antimicrob Agents Chemother 42:2759-2761.

182. Stalder R, Caspers P, Olasz F, Arber W. 1990. The N-terminal domain of the insertion sequence 30 transposase interacts specifically with the terminal inverted repeats of the element. J Biol Chem 265:37573762 .

183. Nagy Z, Szabó M, Chandler M, Olasz F. 2004. Analysis of the Nterminal DNA binding domain of the IS30 transposase. Mol Microbiol 54:478-488.

184. Olasz F, Stalder R, Arber W. 1993. Formation of the tandem repeat (IS30) 2 and its role in IS30- mediated transpositional DNA rearrangements. Mol Gen Genet 239:177-187.

185. Olasz F, Farkas T, Stalder R, Arber W. 1997. Mutations in the carboxy-terminal part of IS30 transposase affect the formation and dissolution of (IS30)2 dimer. FEBS Lett 413:453-461.

186. Kiss J, Olasz F. 1999. Formation and transposition of the covalently closed IS30 circle: the relation between tandem dimers and monomeric circles. Mol Microbiol 34:37-52.

187. Kiss J, Szabo M, Olasz F. 2003. Site-specific recombination by the DDE family member mobile element IS30 transposase. Proc Natl Acad Sci USA 100:15000-15005.

188. Szeverenyi I, Nagy Z, Farkas T, Olasz F, Kiss J. 2003. Detection and analysis of transpositionally active head-to-tail dimers in three additional Escherichia coli IS elements. Microbiology 149:1297-1310.

189. Kiss J, Nagy Z, Toth G, Kiss GB, Jakab J, Chandler M, Olasz F. 2007. Transposition and target specificity of the typical IS30 family element IS1655 from Neisseria meningitidis. Mol Microbiol 63:17311747.

190. Szabó M, Kiss J, Nagy Z, Chandler M, Olasz F. 2008. Sub-terminal Sequences Modulating IS30 Transposition in Vivo and in Vitro. J Mol Biol 375:337-352.

191. Hwa V, Shoemaker NB, Salyers AA. 1988. Direct repeats flanking the Bacteroides transposon Tn4351 are insertion sequence elements. J Bacteriol 170:449-451.

192. Brynestad S, Granum PE. 1999. Evidence that Tn5565, which includes the enterotoxin gene in Clostridium perfringens, can have a circular form which may be a transposition intermediate. FEMS Microbiol Lett 170:281-286.

193. Machida Y, Sakurai M, Kiyokawa S, Ubasawa A, Suzuki Y, Ikeda JE. 1984. Nucleotide sequence of the insertion sequence found in the T-DNA 
region of mutant Ti plasmid pTiA66 and distribution of its homologues in octopine Ti plasmid. Proc Natl Acad Sci USA 81:7495-7499.

194. Gourbeyre E, Siguier P, Chandler M. 2010. Route 66: investigations into the organisation and distribution of the IS66 family of prokaryotic insertion sequences. Res Microbiol 161:136-143.

195. Egelseer EM, Idris R, Jarosch M, Danhorn T, Sleytr UB, Sara M. 2000. ISBst12, a novel type of insertion-sequence element causing loss of S- layer-gene expression in Bacillus stearothermophilus ATCC 12980. Microbiology 146(Pt 9):2175-2183.

196. Han CG, Shiga Y, Tobe T, Sasakawa C, Ohtsubo E. 2001. Structural and functional characterization of IS679 and IS66-family elements. J Bacteriol 183:4296-4304.

197. Haren L, Polard P, Ton-Hoang B, Chandler M. 1998. Multiple oligomerisation domains in the IS911 transposase: a leucine zipper motif is essential for activity. J Mol Biol 283:29-41.

198. Dordet Frisoni E, Marenda MS, Sagné E, Nouvel LX, Guérillot R, Glaser P, Blanchard A, Tardy F, Sirand-Pugnet P, Baranowski E, Citti C. 2013. ICEA of Mycoplasma agalactiae: a new family of self-transmissible integrative elements that confers conjugative properties to the recipient strain. Mol Microbiol 89:1226-1239.

199. Hennig S, Ziebuhr W. 2010. Characterization of the Transposase Encoded by IS256, the Prototype of a Major Family of Bacterial Insertion Sequence Elements. J Bacteriol 192:4153-4163.

200. Yuan Y-W, Wessler SR. 2011. The catalytic domain of all eukaryotic cut-and-paste transposase superfamilies. Proc Natl Acad Sci USA 108: 7884-7889.

201. Lyon BR, Gillespie MT, Skurray RA. 1987. Detection and characterization of IS256, an insertion sequence in Staphylococcus aureus. J Gen Microbiol 133:3031-3038.

202. Lyon BR, May JW, Skurray RA. 1984. Tn4001: a gentamicin and kanamycin resistance transposon in Staphylococcus aureus. Mol Gen Genet 193:554-556.

203. Loessner I, Dietrich K, Dittrich D, Hacker J, Ziebuhr W. 2002. Transposase-dependent formation of circular IS256 derivatives in Staphylococcus epidermidis and Staphylococcus aureus. J Bacteriol 184:47094714.

204. Eisen JA, Benito MI, Walbot V. 1994. Sequence similarity of putative transposases links the maize Mutator autonomous element and a group of bacterial insertion sequences. Nucleic Acids Res 22:2634-2636.

205. Hua-Van Al, Capy P. 2008. Analysis of the DDE Motif in the Mutator Superfamily. J Mol Evol 67:670-681.

206. Prudhomme M, Turlan C, Claverys JP, Chandler M. 2002. Diversity of Tn4001 transposition products: the flanking IS256 elements can form tandem dimers and IS circles. J Bacteriol 184:433-443.

207. Feng X, Bednarz AL, Colloms SD. 2010. Precise targeted integration by a chimaeric transposase zinc-finger fusion protein. Nucl Acids Res 38:1204-1216.

208. Cassier-Chauvat C, Poncelet M, Chauvat F. 1997. Three insertion sequences from the Cyanobacterium synechocystis PCC6803 support the occurrence of horizontal DNA transfer among bacteria. Gene 195:257-266. 209. Dawson A, Finnegan DJ. 2003. Excision of the Drosophila mariner transposon mos1. Comparison with bacterial transposition and $\mathrm{v}(\mathrm{d}) \mathrm{j}$ recombination. Mol Cell 11:225-235.

210. Richardson JM, Dawson A, O’Hagan N, Taylor P, Finnegan DJ, Walkinshaw MD. 2006. Mechanism of Mos1 transposition: insights from structural analysis. EMBO J 25:1324-1334.

211. Tenzen T, Ohtsubo E. 1991. Preferential transposition of an IS630associated composite transposon to TA in the 5'-CTAG-3' sequence. J Bacteriol 173:6207-6212.

212. Lopez de Felipe F, Magni C, de Mendoza D, Lopez P. 1996. Transcriptional activation of the citrate permease $\mathrm{P}$ gene of Lactococcus lactis biovar diacetylactis by an insertion sequence- like element present in plasmid pCIT264. Mol Gen Genet 250:428-436.
213. Kato N, Yamazoe K, Han CG, Ohtsubo E. 2003. New insertion sequence elements in the upstream region of cfiA in imipenem-resistant Bacteroides fragilis strains. Antimicrob Agents Chemother 47:979-985.

214. Podglajen I, Breuil J, Rohaut A, Monsempes C, Collatz E. 2001. Multiple mobile promoter regions for the rare carbapenem resistance gene of Bacteroides fragilis. J Bacteriol 183:3531-3535.

215. de Las Rivas B, Marcobal A, Gomez A, Munoz R. 2005. Characterization of ISLpl4, a functional insertion sequence in Lactobacillus plantarum. Gene 363:202-210.

216. Takemura H, Horinouchi S, Beppu T. 1991. Novel insertion sequence IS1380 from Acetobacter pasteurianus is involved in loss of ethanoloxidizing ability. J Bacteriol 173:7070-7076.

217. Dumontier S, Trieu-Cuot P, Berche P. 1998. Structural and Functional Characterization of IS1358 from Vibrio cholerae. J Bacteriol 180:6101-6106.

218. Davis IJ, Roberts AP, Ready D, Richards H, Wilson M, Mullany P. 2005. Linkage of a novel mercury resistance operon with streptomycin resistance on a conjugative plasmid in Enterococcus faecium. Plasmid 54:26-38.

219. Christie-Oleza JA, Nogales B, Lalucat J, Bosch R. 2010. TnpR encoded by an ISPpu12 isoform regulates transposition of two different ISL3-like insertion sequences in Pseudomonas stutzeri after conjugative interaction. J Bacteriol 192:1423-1432.

220. Kallastu A, Hõrak R, Kivisaar M. 1998. Identification and Characterization of IS1411, a New Insertion Sequence Which Causes Transcriptional Activation of the Phenol Degradation Genes in Pseudomonas putida. J Bacteriol 180:5306-5312.

221. Christie-Oleza JA, Nogales B, Martin-Cardona C, Lanfranconi MP, Alberti S, Lalucat J, Bosch R. 2008. ISPst9, an ISL3-like insertion sequence from Pseudomonas stutzeri AN10 involved in catabolic gene inactivation. Int Microbiol 11:101-110.

222. Vertes A, Asai Y, Inui M, Kobayashi M, Yukawa H. 1995. The Corynebacterial insertion sequence IS31831 promotes formation of an excised transposon fragment. Biotechnol Lett 17:1143-1148.

223. Grindley NDF. 2002. The movement of Tn3-like elements: transposition and cointegrate resolution, p 230-271. In Craig NL, Craigie R, Gellert M, Lambowitz A (ed), Mobile DNA II. ASM Press, Washington DC.

224. Fulks KA, Marrs CF, Stevens SP, Green MR. 1990. Sequence analysis of the inversion region containing the pilin genes of Moraxella bovis. J Bacteriol 172:310-316.

225. Rozsa FW, Meyer TF, Fussenegger M. 1997. Inversion of Moraxella lacunata type 4 pilin gene sequences by a Neisseria gonorrhoeae sitespecific recombinase. J Bacteriol 179:2382-2388.

226. Skaar EP, Lecuyer B, Lenich AG, Lazio MP, Perkins-Balding D, Seifert HS, Karls AC. 2005. Analysis of the Piv recombinase-related gene family of Neisseria gonorrhoeae. J Bacteriol 187:1276-1286.

227. Lauf U, Muller C, Herrmann H. 1999. Identification and characterisation of IS1383, a new insertion sequence isolated from Pseudomonas putida strain H [In Process Citation]. FEMS Microbiol Lett 170:407-412. 228. Tobiason DM, Buchner JM, Thiel WH, Gernert KM, Karls AC. 2001. Conserved amino acid motifs from the novel Piv/MooV family of transposases and site-specific recombinases are required for catalysis of DNA inversion by Piv. Mol Microbiol 39:641-651.

229. Tobiason DM, Lenich AG, Glasgow AC. 1999. Multiple DNA binding activities of the novel site-specific recombinase, Piv, from Moraxella lacunata. J Biol Chem 274:9698-9706.

230. Higgins BP, Carpenter CD, Karls AC. 2007. Chromosomal context directs high-frequency precise excision of IS492 in Pseudoalteromonas atlantica. Proc Natl Acad Sci USA 104:1901-1906.

231. Prosseda G, Latella MC, Casalino M, Nicoletti M, Michienzi S, Colonna B. 2006. Plasticity of the P junc promoter of ISEc11, a new insertion sequence of the IS1111 family. J Bacteriol 188:4681-4689. 
232. Henderson DJ, Lydiate DJ, Hopwood DA. 1989. Structural and functional analysis of the mini-circle, a transposable element of Streptomyces coelicolor A3(2). Mol Microbiol 3:1307-1318.

233. Smokvina T, Henderson DJ, Melton RE, Brolle DF, Kieser T, Hopwood DA. 1994. Transposition of IS117, the $2.5 \mathrm{~kb}$ Streptomyces coelicolor A3(2) 'minicircle': roles of open reading frames and origin of tandem insertions. Mol Microbiol 12:459-468.

234. Muller C, Lauf U, Hermann H. 2001. The inverted repeats of IS1384, a newly described insertion sequence from Pseudomonas putida strain $\mathrm{H}$, represent the specific target for integration of IS1383. Mol Genet Genom 265:1004-1010.

235. Bartlett DH, Silverman M. 1989. Nucleotide sequence of IS492, a novel insertion sequence causing variation in extracellular polysaccharide production in the marine bacterium Pseudomonas atlantica. J Bacteriol 171:1763-1766.

236. Higgins BP, Popkowski AC, Caruana PR, Karls AC. 2009. Sitespecific insertion of IS492 in Pseudoalteromonas atlantica. J Bacteriol 191:6408-6414.

237. Mendiola MV, de la Cruz F. 1992. IS91 transposase is related to the rolling-circle-type replication proteins of the pUB110 family of plasmids. Nucleic Acids Res 20:3521-3521.

238. Garcillan-Barcia MP, Bernales I, Mendiola MV, De la Cruz F. 2002. IS91 rolling circle transposition, p 891-904. In Craig NL, Craigie R, Gellert M, Lambowitz A (ed), Mobile DNA, vol II. ASM Press, Washington DC.

239. del Pilar Garcillan-Barcia M, Bernales I, Mendiola MV, de la Cruz F. 2001. Single-stranded DNA intermediates in IS91 rolling-circle transposition. Mol Microbiol 39:494-501.

240. Toleman MA, Walsh TR. 2011. Combinatorial events of insertion sequences and ICE in Gram-negative bacteria. FEMS Microbiol Rev 35:912-935.

241. Kapitonov VV, Jurka J. 2007. Helitrons on a roll: eukaryotic rollingcircle transposons. Trends Genet 23:521-529.

242. Lam S, Roth JR. 1983. IS200: a Salmonella-specific insertion sequence. Cell 34:951-960.

243. Kersulyte D, Krishnan BR, Berg DE. 1992. Nonrandom orientation of transposon Tn5supF insertions in phage lambda. Gene 114:91-96.

244. Kersulyte D, Velapatino B, Dailide G, Mukhopadhyay AK, Ito Y, Cahuayme L, Parkinson AJ, Gilman RH, Berg DE. 2002. Transposable element ISHp608 of Helicobacter pylori: nonrandom geographic distribution, functional organization, and insertion specificity. J Bacteriol 184: 992-1002.

245. Ton-Hoang B, Guynet C, Ronning DR, Cointin-Marty B, Dyda F, Chandler M. 2005. Transposition of ISHp608, member of an unusual family of bacterial insertion sequences. EMBO J 24:3325-3338.
246. Murai N, Kamata H, Nagashima Y, Yagisawa H, Hirata H. 1995. A novel insertion sequence (IS)-like element of the thermophilic bacterium PS3 promotes expression of the alanine carrier protein-encoding gene. Gene 163:103-107.

247. Kersulyte D, Akopyants NS, Clifton SW, Roe BA, Berg DE. 1998. Novel sequence organization and insertion specificity of IS605 and IS606: chimaeric transposable elements of Helicobacter pylori. Gene 223:175186.

248. Pasternak C, Dulermo R, Ton-Hoang B, Debuchy R, Siguier P, Coste G, Chandler M, Sommer S. 2013. ISDra2 transposition in Deinococcus radiodurans is downregulated by TnpB. Mol Microbiol 88:443-455.

249. Gilbert C, Cordaux R. 2013. Horizontal Transfer and Evolution of Prokaryote Transposable Elements in Eukaryotes. Genome Biol Evol $5: 822-832$.

250. Ronning DR, Guynet C, Ton-Hoang B, Perez ZN, Ghirlando R, Chandler M, Dyda F. 2005. Active site sharing and subterminal hairpin recognition in a new class of DNA transposases. Mol Cell 20:143-154.

251. Guynet C, Hickman AB, Barabas O, Dyda F, Chandler M, TonHoang B. 2008. In vitro reconstitution of a single-stranded transposition mechanism of IS608. Mol Cell 29:302-312.

252. Barabas O, Ronning DR, Guynet C, Hickman AB, Ton-Hoang B, Chandler M, Dyda F. 2008. Mechanism of IS200/IS605 family DNA transposases: activation and transposon-directed target site selection. Cell 132:208-220.

253. Hickman AB, James JA, Barabas O, Pasternak C, Ton-Hoang B, Chandler M, Sommer S, Dyda F. 2010. DNA recognition and the precleavage state during single-stranded DNA transposition in D. radiodurans. EMBO J 29:3840-3852.

254. He S, Hickman AB, Dyda F, Johnson NP, Chandler M, Ton-Hoang B. 2011. Reconstitution of a functional IS608 single-strand transpososome: role of non-canonical base pairing. Nucleic Acids Res 39:85038512.

255. He S, Guynet C, Siguier P, Hickman AB, Dyda F, Chandler M, TonHoang B. 2013. IS200/IS605 family single-strand transposition: mechanism of IS608 strand transfer. Nucleic Acids Res 41:3302-3313.

256. Boocock MR, Rice PA. 2013. A proposed mechanism for IS607family serine transposases. Mob DNA 4:24.

257. Van Duyne GD, Rutherford K. 2013. Large serine recombinase domain structure and attachment site binding. Crit Rev Biochem Mol Biol 48:476-491

258. Kersulyte D, Mukhopadhyay AK, Shirai M, Nakazawa T, Berg DE. 2000. Functional organization and insertion specificity of IS607, a chimeric element of Helicobacter pylori. J Bacteriol 182:5300-5308.

259. Haren L, Ton-Hoang B, Chandler M. 1999. Integrating DNA: transposases and retroviral integrases. Annu Rev Microbiol 53:245-281. 